\title{
Does radical-right success make the political debate more negative?
}

\author{
Vicente Valentim ${ }^{\dagger}$, Tobias Widmann ${ }^{\ddagger \S}$ \\ July 7,2020
}

\begin{abstract}
Political rhetoric has important effects on the quality of democracy, but we know very little about what causes variation in the tone of the political debate. We investigate how radical-right success affects the way the remaining politicians discuss political issues. Using an original dictionary, we measure different positive and negative emotions in a newly collected dataset of speeches in German state parliaments. Taking advantage of variation in the timing of elections when radical-right politicians enter these parliaments, we find that politicians of other parties respond to radical-right success by using more positive, instead of negative, emotions. A mix of quantitative and qualitative analyses suggest that the increase in positive emotions is used strategically for politicians to distance themselves from radical-right discourse. Our findings highlight how radical-right success can create incentives for other politicians to enforce norms that radical-right politicians breach.
\end{abstract}

Keywords: Negative political rhetoric, emotions, radical right, legislative behavior, dictionary approaches, Germany.

A pre-registration of this paper can be found here.

\footnotetext{
${ }^{*}$ We thank Daniel Bischof, Francesco Colombo, Catherine De Vries, Elias Dinas, Miriam Golden, Jonne Kamphorst, Joe Kendall, Christina la Cour, Levente Littvay, Sergi Martínez, Kasia Nalewajko, Fred Paxton, Judith Spirig, António Valentim, Annabelle Wittels, and Eleanor Florence Woodhouse for extremely helpful comments on earlier versions of the manuscript.

${ }^{\dagger}$ European University Institute, Department of Political and Social Sciences, Villa Sanfelice, San Domenico di Fiesole, I-50014, Italy. Email: vicente.valentim@eui.eu.

${ }_{\ddagger}^{\ddagger}$ European University Institute, Department of Political and Social Sciences, Villa Sanfelice, San Domenico di Fiesole, I-50014, Italy. Email: tobias.widmann@eui.eu.

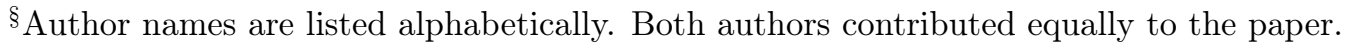


What explains variation in the overall tone of the political debate? A large body of research has shown that the communicative style with which the political debate is carried has crucial implications for democracy. Negative rhetoric can increase affective polarization (Iyengar, Sood, and Lelkes 2012), affect voter turnout (Ansolabehere et al. 1994; Lau and Pomper 2001), influence how individuals assess the parties competing for an election (Pattie et al. 2011), make minorities withdraw from public life (Hobbs and Lajevardi 2019) and affect their mental health (Chavez et al. 2019). Despite these important consequences, we still know very little about what causes variation in the tone of the public debate.

In this paper, we focus on how the success of radical-right politicians affects the political debate. Radical-right politicians are becoming increasingly successful across the world. They have risen to power in countries such as the United States, Brazil, or the Philippines. Virtually all European countries have a radical-right party with parliamentary representation. Their success has been shown to shift the policy positions of the remaining candidates (Abou-Chadi and Krause 2018; Abou-Chadi 2016), affect the preferences of voters (Schain 2006), polarize the electorate (Bischof and Wagner 2019), put new issues in the political agenda (Hobolt and De Vries 2015), and normalize previously stigmatized behavior (Bursztyn, Egorov, and Fiorin 2017; Valentim 2018). One of the most distinctive characteristics of radical-right candidates is their rhetoric, which makes extensive use of negative emotions (Widmann 2019).

How does this success affect the rhetoric of the remaining politicians? We answer this question with resource to a newly-collected dataset of over 100,000 speeches in German state parliaments. We analyze these speeches using an original dictionary that measures the use of different discrete positive and negative emotions. This novel emotional dictionary has been specifically created to capture discrete emotions in German political 
text, taking into consideration language-specific grammar. Importantly, it allows us to measure different discrete emotions, instead of just looking at positive and negative sentiment. This is a crucial step because previous research has shown that different positive and negative emotions can differ starkly in their behavioral effects. We report a set of crowdsourcing validation tests that compare dictionary results to human coders, showing that our dictionary outperforms off-the-shelf dictionaries when it comes to measuring emotional language in German political text.

Taking advantage of variation in the timing of elections that granted representation in state parliaments to politicians of the radical-right party Alternative for Germany (AfD), we employ fixed-effects models (with time period and politician fixed effects) to estimate the effect of radical-right success on the use of emotions by the remaining politicians. Far from showing a contagion or normalization effect, our findings support a distancing effect: not only does the success of radical-right politicians not make the remaining politicians use more negative emotions, it makes them use more positive emotions. After radicalright politicians enter parliament, speeches by the remaining politicians become more hopeful, enthusiastic, joyful, and proud. This effect is large - between 0.8 and 1.4 standard deviations, depending on the specific outcome one focuses on. The stronger effect is on hope and enthusiasm, emotions frequently employed to mobilize voters, providing initial evidence that the increased use of positive emotions as a response to radical-right success may be strategic.

A set of additional quantitative and qualitative analyses provide further evidence suggesting that the increasing use of positive emotions may be part of a conscious strategy by which the remaining politicians build a contrast between themselves and the radical right, who they call out on the breaching of established norms regulating the political debate. We start with quantitative analyses that test for two observable implications of the distancing mechanism. Supporting this mechanism we find that (1) the effect is stronger on mainstream politicians (as opposed to populist ones), who have a stronger incentive to portray themselves as guardians of norms breached by the radical right; 
and that (2) among mainstream politicians, the effect is stronger for those left of center, whose values are more threatened by radical-right success. We also find evidence that the increased use of positive emotions by established politicians effectively counterbalances the increased negativity that the radical right brings to the political debate, keeping it from becoming more negative overall.

We complement these tests with qualitative analyses of speeches in our data. We find clear examples of politicians explicitly calling out the radical-right rhetoric as unacceptable and norm-breaching. They also make efforts to distance themselves from such rhetoric. The use of positive emotions is instrumental in building a contrast between themselves and their party and radical-right politicians, and in mobilizing voters to stand up against the norm-breaching radical-right rhetoric. We then check whether these anecdotes represent a pattern in our data by analysing a random sample of speeches in our data that took place after radical-right politicians entered parliament and that make extensive use of positive emotions. This sample shows ample evidence of politicians calling out the norm-breaching behavior of the radical-right as unacceptable, both in its general way of doing politics and in its legislative debate, and marking a clear contrast between themselves and the radical right - most often, by employing positive emotions.

Finally, we test for an alternative mechanism - that the effect is driven simply by radical-right success increasing the salience of issues to which the remaining politicians attach positive emotions. Running against this argument, we find that MPs increase their use of positive emotions both on issues that radical-right politicians discuss often and on issues they discuss more rarely.

These findings have important implications for the literature. Previous research has provided extensive evidence of how the success of radical-right candidates can make other politicians adopt more conservative policy positions. Our study suggests that the same is not true when it comes to their rhetorical style, in regard to which the remaining politicians (especially those of mainstream parties) try to distance themselves from their radical-right contenders. This conclusion has important implications for the quality of 
democracy. A negative debate erodes the possibility for constructive deliberation and opens the doors to affective polarization (Iyengar, Sood, and Lelkes 2012). The fact that mainstream politicians react to radical-right success by using more positive emotions lowers concerns that such success can give rise to spirals of negativeness with detrimental consequences for democracy.

\section{Radical-right success and the political debate}

This study bridges two hitherto unconnected strands of literature. The first is the literature on the use of emotional appeals by politicians, which has mostly focused on how such appeals affect voters. The second is the literature on how established politicians react to the success of radical-right contenders, which has mostly focused on the effect of such success on issue salience and policy positions, to the detriment of rhetorical style.

Previous studies on the effects of emotional appeals by politicians have shown such appeals to have a number of important effects. Negative campaigns can affect voter turnout, even if the exact nature of this relation is still disputed (Ansolabehere et al. 1994; Lau and Pomper 2001; Iyengar, Sood, and Lelkes 2012). The use of emotional rhetoric by politicians has also been shown to affect how individuals engage in electoral campaigns and consume pieces of news (Gadarian and Albertson 2014; Valentino et al. 2008; Brader 2005), the cognitive process by which voters make up their minds about politics (Brader 2005; Vasilopoulos, Marcus, and Foucault 2018), their development of political attitudes (Brader, Valentino, and Suhay 2008; Rico, Guinjoan, and Anduiza 2017; Vasilopoulos, Marcus, and Foucault 2018), and their vote choices (Valentino et al. 2011; Brader 2005; Vasilopoulos et al. 2019).

Despite these important insights, this literature has mostly neglected that emotional appeals can also affect other politicians. Concretely, the success of radical-right politicians, with their distinctive negative rhetoric, can be expected to significantly alter the use of emotions by established politicians. Established politicians can be expected to 
react to radical-right success because, as previous research has shown, they take previous elections as sources of information that help them define their strategy (Abou-Chadi and Orlowski 2016; Somer-Topcu 2009). As this literature has shown, radical-right politicians emphasize previously neglected issues in the political agenda (Hobolt and De Vries 2015; De Vries and Hobolt 2012) and, as a response to their success, the remaining politicians tend to assume more rightist policy positions (Abou-Chadi 2016; Han 2015; Bale 2003; Abou-Chadi and Krause 2018).

Radical-right politicians, however, do not just innovate in the choice of issues they politicize or their position on those issues. The specific way in which they discuss those issues is also novel. Their rhetoric relies heavily on the use of negative emotions - in contrast to the political discourse of other politicians, especially incumbents, who tend to use positive emotions more often (Widmann 2019; Crabtree et al. 2018). In facing the electoral success of radical-right contenders, the remaining politicians can face uncertainty as to whether such success was driven by their policy positions or their rhetorical style. As a consequence, they may opt to get closer to both: not only move their policy positions closer to those of the radical right, but also try to emulate their discursive style.

Furthermore, the success of radical-right politicians can also affect the rhetoric of the remaining politicians through a process of social norm change. Like other realms of social life, the political debate and legislative sessions are regulated by norms that dictate which sets of behaviors are deemed appropriate (Huitt 1957; Mayntz 1992; Franceschet 2010; Rush and Giddings 2011). Descriptive norms - i.e., what others do, as opposed to what others think should be done-have been shown to be a particularly strong predictor of behavior (Bicchieri and Xiao 2009). In observing that mainstream politicians tend to use positive emotions, MPs inclined to use negative emotional appeals in their discourse might refrain from doing so because that is not the modal form of communication in the political debate - in other words, it does not correspond to the descriptive norm in the political debate. Radical-right politicians explicitly breach a number of established norms (Mudde 2004, p. 554), and previous research has found that their success can 
normalize previously stigmatized behavior (Bursztyn, Egorov, and Fiorin 2017; Valentim 2018). There are two reasons why one might the parliamentary entry of the radical right to exert similar effect upon political elites. In the first place, the social norms regulating the political debate are, in many ways, similar to the ones regulating other realms of social life (Bernick and Wiggins 1983), and hence one might expect them to change through similar mechanisms. In the second place, changes in the balance of power within legislative bodies have been shown to be predictive of changes in the norms regulating behavior in those bodies (Jewett 2002). For these reasons, one might expect that, like voters, politicians can take radical right success as a cue that the kind of discourse that characterizes the radical right has become normalized. As a consequence, MPs are likely to regard the negative rhetoric that characterizes radical-right discourse as a more tenable discursive strategy. This leads us to formulate our first hypothesis:

Imitation hypothesis: The success of radical right candidates will make other politicians use more negative emotions.

There are, however, reasons to expect the opposite effect as well. Established politicians may feel like radical-right contenders have ownership over the negative rhetoric they employ, making it a risky strategy for them to imitate it. Instead, a more profitable strategy may be for established politicians to reinvent themselves around the kind of rhetoric they have ownership on, such as their commitment to established values and norms (De Vries and Hobolt 2020, pp. 250-251). Given the detrimental effects that negative rhetoric has on the quality of democracy, established politicians may choose to distance themselves from the the negativity brought about by the radical right. One way by which they can do so is to use an increasingly positive style of debating. That would allow them to build a clear contrast with the negative debate of the radical right, and might signal their commitment to established norms that the radical right openly breaches.

This distancing strategy may be rational due to its potential effect in containing 
the electoral wins of the radical right. Negative emotions have been shown to affect a number of individual-level covariates that can make an individual more likely to cast a vote for the populist right. Anxiety can lead to conspiracy thinking about minorities (Grzesiak-Feldman 2013); while anger can reduce support for immigration among whites (Brader, Valentino, and Suhay 2008), make individuals develop populist attitudes (Rico, Guinjoan, and Anduiza 2017), and increase authoritarian views among right-wing individuals (Vasilopoulos, Marcus, and Foucault 2018). Moreover, fear has also been shown to directly increase the probability that an individual will vote for far-right parties (Vasilopoulos et al. 2019). For these reasons, the remaining politicians may have an incentive to respond to radical-right success by increasing their use of positive emotions to try and contain the effect that the negative rhetoric of the radical right may have in fueling further support for it.

The incentives that radical-right success generates for the remaining politicians to increase the use of positive emotions in their discourse, however, should not be homogeneous across politicians of the whole ideological spectrum. In the first place, the effect should be stronger on MP's of mainstream parties than on those of populist parties. While mainstream parties tend to mobilize on using positive emotions, populist politicians of both the left and the right tend to use negative emotions as a ways of mobilizing on discontentment with the establishment (Crabtree et al. 2018; Widmann 2019). As a consequence, unlike with mainstream parties, the increase in negativity brought about by the success of radical-right politicians may actually prove profitable to left populist politicians. For this reason, the strategic incentives that could lead mainstream parties to counterbalance the negativity of the radical right as a ways of containing its electoral success do not apply to populist parties. In the German case, this means that the effect should be weaker on MPs of the left-populist party The Left, as compared to the remaining politicians.

Moreover, among mainstream parties, the effect should depend on the ideology of the politician. Left-wing politicians are the ones whose values are most threatened by 
radical right discourse. Indeed, previous research has shown that, when political actors are successful in pushing for changes in the status quo, it is actors at the other end of the ideological spectrum who react by moving even farther in the opposite direction (Bustikova 2014). Moreover, the voter who support these politicians are also likely to be the ones who more strongly react by condemning radical-right discourse. As Bischof and Wagner (2019) show, after an initial legitimization effect, radical-right success leads to a backlash effect brought about by left-wing individuals becoming more likely to enforce the norms that the radical-right breaches. Consequently, if mainstream politicians react to radical-right success by strategically counterbalancing their negative rhetoric, the effect should be stronger on MP's of left-wing parties, who have have stronger intrinsic (their own values) and strategic (their voters' reactions) motivations to distance themselves from the radical right. This leads us to formulate our second hypothesis:

Distancing hypothesis: The success of radical right candidates will make other politicians use more positive emotions. This effect should be stronger on politicians of mainstream parties and, among those, on politicians of the center-left. ${ }^{1}$

\section{Data and Empirical strategy}

We study whether the success of radical-right candidates makes the political debate more negative by drawing upon the case of Germany. Germany represents a good case study for two main reasons. In the first place, it has recently witnessed the first-time success of the radical-right party Alternative for Germany (AfD). Founded in 2013, this party narrowly missed the electoral threshold in the federal election of September that year, remaining without parliamentary representation. Starting out as an Eurosceptic party, the AfD quickly moved further to the right, becoming a clearly radical-right party (Arzheimer

\footnotetext{
${ }^{1}$ The second part of this hypothesis was not included in our pre-analysis plan, which made reference to the main effect alone. Moreover, the title of this hypothesis was slightly different in the pre-analysis plan. Appendix A in the Online Appendix lists these deviations from the pre-registration, along with the rationale for them.
} 
and Berning 2019). In 2017, it entered national parliament and became the third most voted party.

Secondly, Germany provides us with variation in the timing of state elections, which we can use to estimate the effect of the parliamentary presence of radical-right politicians. Germany is a federal state where each of the 16 states has its own parliament. The fact that elections for state parliaments are not synchronized allows us to estimate the effect of the parliamentary presence of radical-right politicians (coded as all politicians elected by the AfD) on the behavior of the remaining state MPs - a design that has been used in previous studies drawing upon different outcomes (De Vries and Hobolt 2020, pp. 204220). Parliamentary entry is a standard measure of electoral success that has been used in a number of previous studies (e.g. Dinas, Riera, and Roussias 2015; Dinas and Foos 2017; Abou-Chadi and Krause 2018; Abou-Chadi 2016; Bischof and Wagner 2019). Table 1 shows the dates of the state elections included in our sample, and the vote share and seat share AfD got in them.

Table 1: Dates of German state elections included in the analyses.

\begin{tabular}{ccc}
\hline \hline State & Date of state election & Vote share for AfD \\
\hline Baden-Württemberg & March 13, 2016 & 15.1 \\
Bavaria & October 14, 2018 & 10.2 \\
Berlin & September 18, 2016 & 14.2 \\
Brandenburg & September 14, 2014 & 12.2 \\
Bremen & May 10, 2015 & 5.5 \\
Hamburg & February 15, 2015 & 6.1 \\
Hessen & October 28, 2018 & 13.1 \\
Lower Saxony & October 15, 2015 & 6.2 \\
Mecklenburg-Vorpommern & September 4, 2016 & 20.8 \\
North Rhine-Westphalia & May 14, 2017 & 7.4 \\
Rhineland-Palatinate & March 13, 2016 & 12.6 \\
Saarland & September 4, 2016 & 6.2 \\
Saxony & August 31, 2014 & 9.7 \\
Saxony-Anhalt & March 13, 2016 & 24.2 \\
Schleswig-Holstein & May 7, 2017 & 5.9 \\
Thuringia & September 14, 2014 & 10.6 \\
\hline
\end{tabular}

The outcome variables in our empirical analyses are measured with resource to an original dataset composed of all speeches in the 16 German state parliaments between 
January 12014 and June 1 2019, collected from the official site of each state parliament. We removed speeches with length under 100 words, as these were mainly interjections and questions from the plenary audience rather than actual speeches. ${ }^{2}$ We only included speeches from major parties that are represented at the federal level. In addition, we excluded speeches from members of the state government and focus solely on MPs. This leaves us with a sample of 101,844 speeches. We rely on parliamentary speeches as a data source because they represent the way politicians actually communicate during the political debate. We believe this approach to be a better way of measuring the overall tone of the political debate than alternatives such as the use of party manifestos. While a readily available source of data, manifestos are usually not read by voters and are less likely to influence them. Moreover, they also present the shortcoming of being released only in election years (Sagarzazu and Klüver 2017). Finally, they often include topics that have very low salience for the parties, and have been shown to be inaccurate in the ideological placement of the parties (Dinas and Gemenis 2010).

To measure how much these speeches make use of positive and negative emotions, we rely on a dictionary approach. We use a novel emotional dictionary ("ed8") that has been specifically created to measure discrete emotional language in political text, while taking into consideration German language peculiarities. The ed8 dictionary is based on the augmented dictionary (Rauh 2018), a German sentiment dictionary that reliably discriminates positive and negative tone in German political language. However, the augmented dictionary cannot differentiate between discrete emotions - which is important since different emotions (even of the same valence) can lead to diverse impact on information processing, attitude formation, and the behavior of voters (Rico, Guinjoan, and Anduiza 2017; Kühne and Schemer 2015; Valentino et al. 2008; Valentino et al. 2011; Vasilopoulos et al. 2019; Vasilopoulou and Wagner 2017). We thus extended this dictionary with separate categories that attribute words to eight different emotions: anger,

\footnotetext{
${ }^{2}$ To make sure this decision is not driving the results, Figure D.5 in the Online Appendix replicates the main analyses without removing these speeches.
} 
fear, disgust, sadness, joy, enthusiasm, pride, and hope. ${ }^{3}$

To compare the accuracy of the dictionary, we used a German crowd working platform called Crowdguru, which is similar to Amazon's Mechanical Turk. As data, we selected 10,000 sentences coming from two important sources of political communication: parliamentary speeches and Facebook party accounts (for more details on the data sampling see Online Appendix B). The 10,000 sentences were then compiled into microtasks (Human Intelligence Tasks or "HITs") consisting of 10 sentences each. Every HIT included one hidden test question to assess the quality of the crowd coders. Every HIT was assigned to five different coders, which has been found to result in enough judgements per sentences to achieve reasonable precision (Benoit et al. 2016). Simple coding instructions (with example sentences for each emotion) were presented to the coders before coding. The coders then had to decide whether each sentence was associated with one of the eight emotions, with no emotion at all, or whether the sentence is uncodable (e.g. because it is incomprehensible). Multiple answers were possible since statements can be associated with multiple emotions simultaneously.

To ensure valid and reliable data production, it is essential to build in several quality control measures. Similar to recent studies using crowd coding for data production (Benoit et al. 2016; Lehmann and Zobel 2018; Rudkowsky et al. 2018), the validation process included different test questions before and during the coding process to assure a high quality of coding (see Online Appendix B for details). The coded validation sentences serve now as "true" answers and allow us to measure the accuracy of the ed 8 dictionary. Online Appendix B shows the results of this measurement and the comparison to other dictionaries. Overall, the results show that the novel ed8 dictionary applied in this study outperforms widely used off-the-shelf dictionaries in several measures across all comparable emotions. It shows robust F1 scores and substantially improves the accuracy of automated text classification compared to other emotional dictionaries.

Applying the ed 8 to the data provides a score measuring how many words associated

\footnotetext{
${ }^{3}$ Further details on the process of construction of the dictionary and how it adds to existing dictionaries can be found in Appendix B.
} 
with each emotions are found in a given parliamentary speech. For example, a document containing four anger words and two words connected to joy, obtains a value of 4 for anger and 2 for joy. To create comparable scores independent of the length of a given document, normalized emotional scores are created, i.e. dividing the emotional scores by the word count of each document. These normalized scores were then standardized to make comparisons easier. These final standardized scores for each of the eight emotional categories constitute the outcome variables in our analyses. Table D.1 in the Online Appendix shows how the emotions correlate in the speeches that compose our dataset. Figure D.1 in the Online Appendix shows the distribution of these eight outcome variables. ${ }^{4}$ In the case of both positive and negative emotions, we also include a summary index as an outcome, which we obtain from extracting the first principal component of the individual standardized emotion. In so doing, we hope to reduce noise and lower concerns with multiple hypotheses testing (Broockman, Kalla, and Sekhon 2017).

This dataset was then grouped by thirty-day periods, centered around the date of the state election in their country. In this final dataset, the unit of observation is the politician*month-to-election $(n=37,289)$. This means that our dataset gives us information on the average level of emotions used by each MP in their speeches, within a given number of months before or after the state election.

Our empirical analyses rely on models with politician fixed-effects that estimate the effect of the parliamentary presence of radical-right MPs (coded as AfD politicians) on the remaining politicians. A potential concern with one-way fixed-effects models is that there may be periodic fluctuation in the level of emotionality as a function of the distance to the election. Specifically, one might suspect that campaign periods have a level of emotionality that is different from the remaining periods, as research has shown that politicians change their rhetorical strategy in the weeks ahead of elections (Ceccobelli 2018). For this reason, we rely on two-way fixed effects models including month-to-

\footnotetext{
${ }^{4}$ As this Figure shows, the distribution of the outcome variables is rather skewed. For this reason, Figure D.9 in the Online Appendix presents a robustness check using the log-transformation of the dependent variables. The results remain substantively similar to the main ones.
} 
election fixed effects that control for common trends in the level of emotionality for each actor as we move closer and farther from the date of the election. The treatment effect is then calculated according to the following equation:

$$
Y_{i t}=\alpha+\gamma_{i}+\lambda_{t}+\tau D_{i t}+u_{i t}
$$

where $Y_{i t}$ is the level of the dependent variable in speech $i$ at time period $t ; \gamma_{i}$ is a vector of politician-level fixed effects that control for unobserved heterogeneity across MPs; $\lambda_{t}$ is a vector of month-to-election fixed effects; and $\tau$ is the treatment effect.

\section{Findings}

Before we estimate the effect of the presence of radical-right politicians in state parliament, we check whether there is indeed a descriptive difference in use of emotions between politicians of the radical right and the remaining ones. Figure 1 plots the mean score for each emotion in MPs of each of the main German parties. The top row plots negative emotions (anger, fear, disgust, and sadness), while the bottom row plots positive emotions (joy, enthusiasm, pride, and hope). As the Figure makes clear, radical-right politicians (those who belong to the party AfD) tend to use significantly more negative emotions in their rhetoric than do their counterparts from other parties. Regardless of the negative emotion one draws upon, radical-right MPs use it far more often than MPs of any other party.

When we turn to positive emotions, the pattern is the opposite. Radical-right MPs are among the ones using positive emotions less often. The only other party whose MPs use a similarly low amount of positive emotions is the left-populist The Left. This finding is in line with previous research, which has found that populist politicians use positive emotions less often than the mainstream ones (Widmann 2019), and that the rhetoric of parties far from the ideological center also tends to be less positive (Crabtree et al. 2018).

After establishing that radical-right politicians employ a significantly more negative rhetoric than the remaining ones, we turn to estimating the effect of their success on 
Figure 1: Use of different emotions in parliamentary speeches, conditional on the party of the MP.
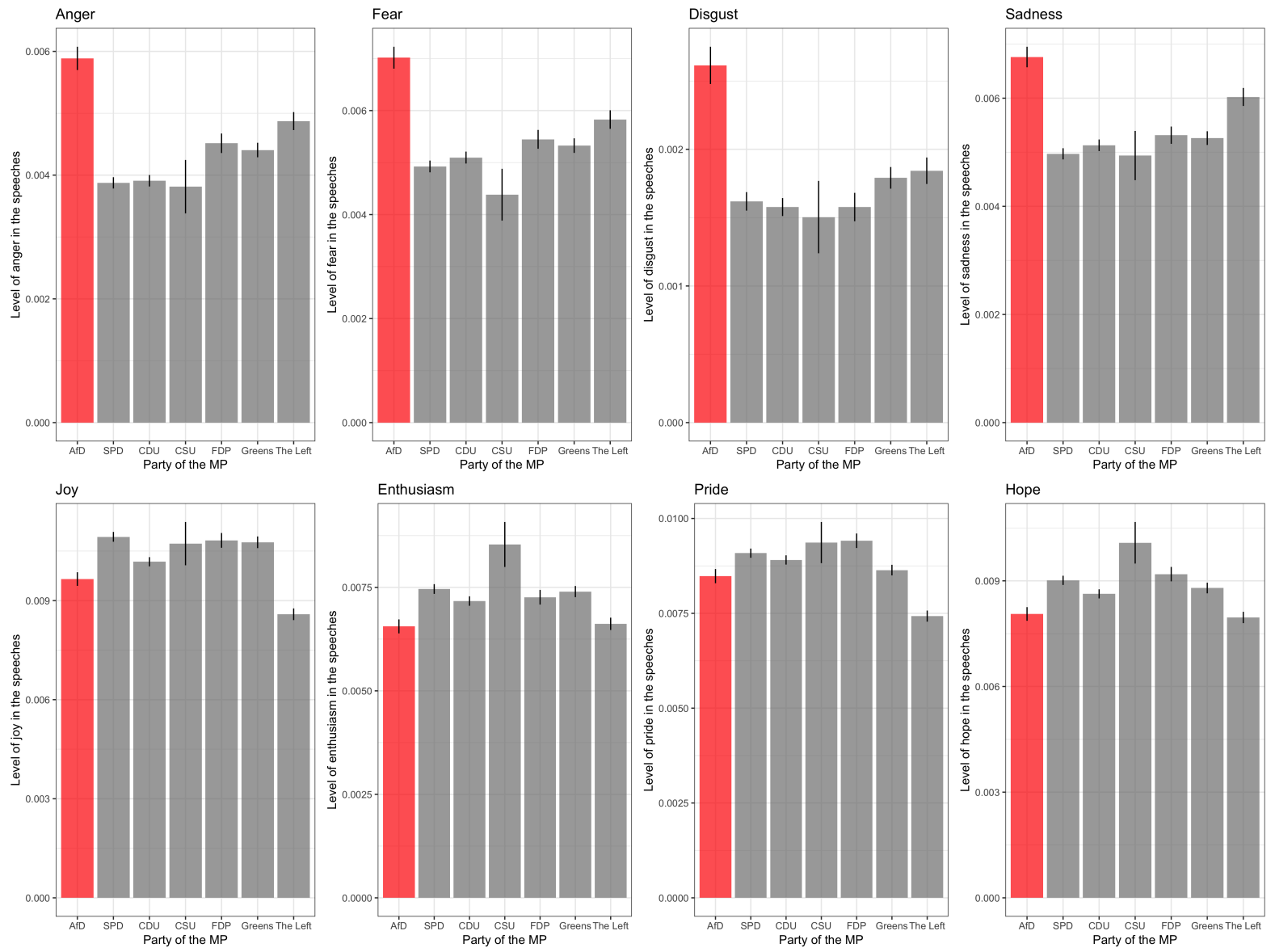

Notes: Lines represent 95\% Confidence Intervals..

the remaining politicians. Figure 2 shows the effect of the parliamentary presence of radical-right MPs on the emotional appeals made by state MPs of other parties in their parliamentary speeches. It shows clear support for the distancing hypothesis, to the detriment of the imitation hypothesis. The parliamentary presence of radical-right MPs increases the use of positive emotions by MPs of the remaining parties; but has no effect on their use of negative emotions. The effect on positive emotions is statistically significant at the $95 \%$ level regardless of the specific sentiment one draws upon. The effects are also large in substantive terms, ranging between around 0.8 standard deviations in the case of pride and around 1.4 standard deviations in the case of the summary measure. In turn, when it comes to negative emotions, all coefficients are very close to zero and far from traditional thresholds of statistical significance. Moreover, the effect is positive for 
some measures and negative for others.

Looking at the effect on each individual emotion also shows interesting patterns. The stronger effects are on hope and enthusiasm. As shown in Figure 1, these are the emotions that radical-right politicians themselves tend to use less often. The fact that the remaining politicians respond to radical-right success by increasing these emotions suggests that they may do so with the aim of creating a sharp distinction between their rhetoric and that of the radical right. At the same time, both of these emotions tend to be used for electoral mobilization (Brader and Marcus 2013; Just, Crigler, and Belt 2007), suggesting that politicians may increase their use of positive emotions as a ways of mobilizing voters against the newly successful radical right and the negativity of its discourse. We explore this mechanism in further detail in the next section.

Figure 2: Effect of the parliamentary presence of radical right MPs on the use of emotional appeals by the remaining MPs.

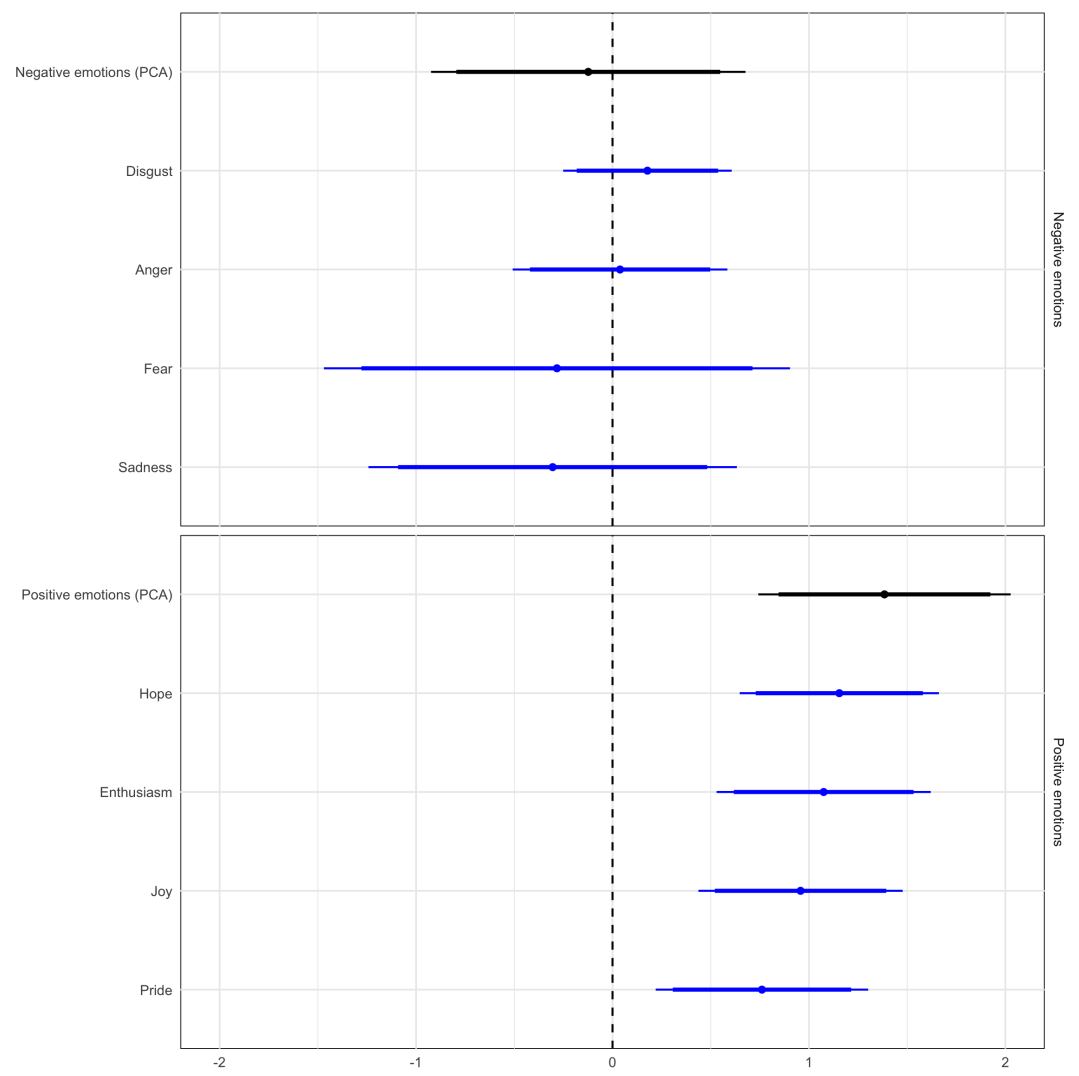

Notes: Thick lines represent 95\% Confidence Intervals; thin lines represent 90\% Confidence Intervals. All dependent variables are standardized. The models include actor-level and months-since-election fixed effects. Standard errors are clustered by actor. 
The Online Appendix provides a number of robustness checks and additional analyses. In the first place, Figures D.2 and D.3 show little evidence of heterogeneity depending on the government or opposition status of the MP's party. To lower concerns stemming from the fact that our main analyses include some MPs that were elected for the first time after the election that also brought the radical right to the state parliament, Figure D. 4 replicates Figure 2 including only MPs that were already in the state parliament in the legislature before radical-right politicians entered it. The results remain very similar. Figure D.5 replicates the main analyses without excluding short speeches (whose length is below 100 words). The results remain substantively identical with this sample, even if the effect sizes become smaller. We also replicate the analyses without grouping the data by monthly periods. In these analyses, we simply group the data by day and then add the month-to-election fixed effects as in the main model shown in Figure 2. As shown in Figure D.6, the results remain very similar. Figure D.7 replicates the main analyses adding calendar-year fixed effects. Again, the results remain very similar to the main ones. Figure D.8 shows that the results remain very similar if we estimate the model with state fixed effects instead of politician fixed effects. Figure D.9 replicates the main analyses using logged dependent variables. Finally, Figure D.10 shows the results of a robustness check where we replicate the analyses after sequentially removing each state from the sample. The results are similar on all subsets of states.

\section{Creating distance towards radical-right politicians? In-}

\section{vestigating the mechanism}

\section{Quantative analyses}

In the previous section we found that, while the parliamentary presence of radical-right MPs does not affect the extent to which MPs of the remaining parties use negative emotions in their speeches, it increases their use of positive emotions - especially hope and 
enthusiasm. As we have argued in the theoretical section, a possible explanation for this finding is that MPs of the remaining parties increase their use of positive emotions to distance themselves from radical-right discourse. In so doing, they get to present themselves as the guardians of democratic norms that the radical-right breaches. Moreover, doing so may contain the future electoral success of the radical, which is likely triggered by an increasingly negative political debate.

To investigate if this is the mechanism in place, we start with conducting subsample analyses that test empirical implications of the distancing mechanism. As argued in the theoretical section, if this is the mechanism in place we should find the effect to be stronger on MP's of mainstream parties - who have more to lose from an increase in the overall negativity of the political debate than do their counterparts from populist parties, who likely profit from this increased negativity. In the case at hand, this means that the effect should be weaker on MP's of the populist left party The Left. On the other hand, among mainstream parties, the effect should be stronger on left-wing MPs, because their values are more affected by the divisive negative discourse of the radical right. Moreover, the strategic incentive for these parties to distance themselves from the negativity brought about by the radical right is stronger, because previous research has shown that its voters themselves tend to react to radical-right success by holding closer to the democratic norms breached by the negative discourse of the radical right (Bischof and Wagner 2019).

We start with testing whether the effect is stronger on MPs of mainstream parties than on their counterparts from populist parties. We do so by replicating the main analyses shown in Figure 2 on two sets of subsamples: one composed of the MPs of the populsit party The Left; and another composed of the MPs of mainstream parties - CDU and CSU, SPD, FDP, and Greens. ${ }^{56}$ We would expect the effect to be much smaller on

\footnotetext{
${ }^{5}$ The coding of the Greens as a mainstream party as opposed to a radical-left party might raise some concerns. However, this party is much more institutionalized than Green parties in other countries and is one of the Green parties in Europe that has deviated the most from the typical model of the party family (Carter 2013). To make sure this choice is not driving the results, in the Online Appendix we replicate these analyses excluding the Greens. As shown in Figure D.11, the results remain very similar.

${ }^{6}$ While we do focus on individuals MPs, previous research provides us with good reasons to believe
} 
MPs of the populist party The Left, the descendant of the ruling party in former East Germany.

The results of these analyses are shown in Figure 3. Supporting the strategic distancing mechanism, the Figure shows a clear difference between MPs from The Left party and those from mainstream parties. The effects are much weaker for MPs of The Left party (upper panel in the Figure) than for MPs of mainstream parties (lower panel in the Figure).

Figure 3: Effect on radical left party The Left and on mainstream parties.

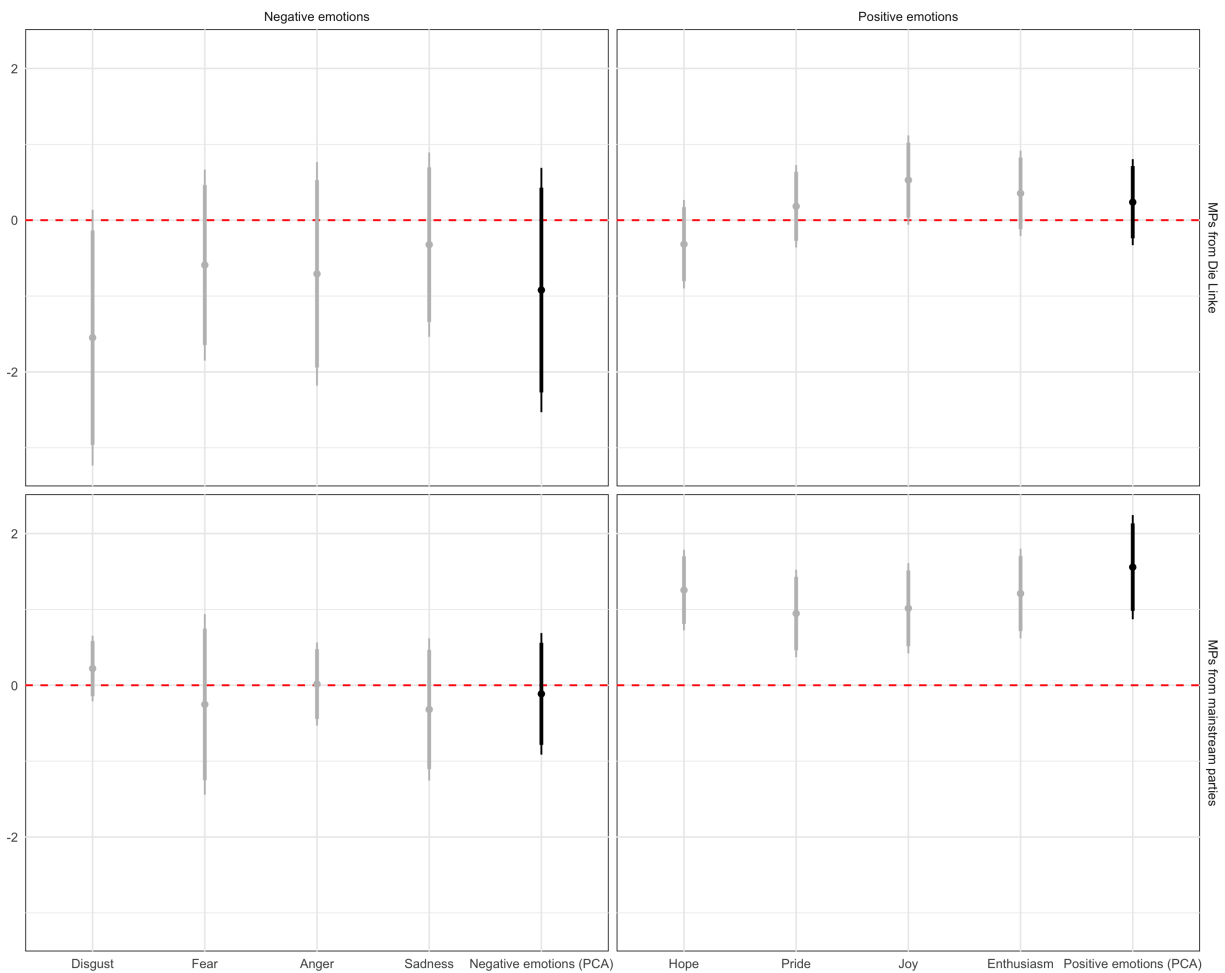

Notes: Thick lines represent 95\% Confidence Intervals; thin lines represent 90\% Confidence Intervals. All dependent variables are standardized. The models include actor-level and months-since-election fixed effects. Standard errors are clustered by actor.

We now look at the second empirical implication of the distancing mechanism - that, amid mainstream politicians, the effect should be stronger on those left-of-center. To do so, we replicate the analyses on another two subsamples composed of MPs from leftwing parties and MPs from right-wing parties. Because we are interested in mainstream that the behavior of German MPs should be affected by their party affiliation (Proksch and Slapin 2012). 
politicians, we remove the party The Left from these analyses. ${ }^{7}$ Thus, we consider as left-wing MPs those who belong to the Greens and the SPD (Social Democrats). We consider as right-wing MPs those who belong to CDU/CSU (Christian Democrats) and FDP (market liberals). As with the main analyses, we remove MPs from the AfD from these subsample analyses. Figure 4 shows the results of these analyses. We find a pattern similar to the one shown in Figure 2 in both subsamples. The success of radicalright politicians increases the use of positive emotions by both left- and right-wing MPs. Supporting the distancing mechanism, however, the effects on the use of positive emotions are stronger for left-wing MPs (upper panel on the Figure), than for right-wing MPs (lower panel on the Figure). For most positive emotions, the coefficient size for left-wing politicians are around twice as large as those for right-wing politicians.

The finding that the remaining politicians seem to respond to radical-right success by strategically increasing their use of positive emotions raises an important question: is such an increase sufficient to make up for the increased negativity that radical-right politicians bring to the debate? To investigate this question, we create a variable that gives us the difference in the values of PCA for negative emotions and those of the PCA for positive emotions. Positive values in this variable mean that the debate has an overall positive tone; negative values mean that the debate has an overall negative tone. Since we are interested in evaluating whether the remaining politicians can counter the negativity brought about by the parliamentary entry of the radical right, we do not remove AfD politicians from these analyses. We then look at the evolution of this variable before and after the state elections that brought the radical right to parliament.

The results of this exercise are shown in Figure 5. As the Figure shows, there is no significant discontinuity in the difference between the use of positive and negative emotions after the state elections that bring the radical right to parliament. These descriptive trends seem to suggest that, in using more positive emotions as a response to the success

\footnotetext{
${ }^{7}$ To make sure this decision is not driving the results, Figure D.12 in the Online Appendix replicates these analyses including MPs from The Left in the subsample of left-wing MPs. The difference between left- and right-wing politicians is still clear, even if slightly smaller than the one shown in Figure 4 below - as one would expect, considering that Figure 3 showed no effect on MPs of The Left.
} 
Figure 4: Effect conditional on the ideology of the MPs.

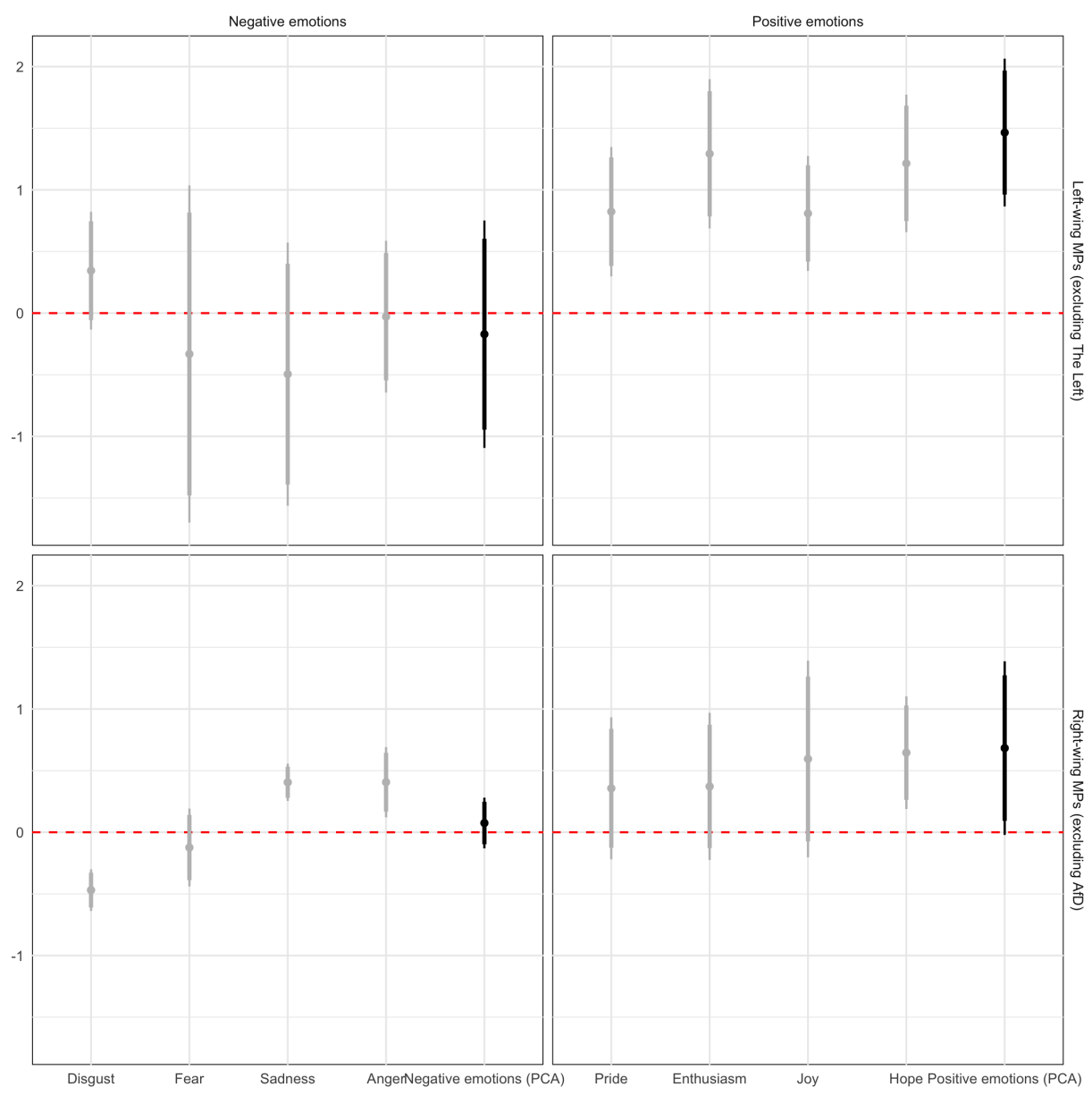

Notes: Thick lines represent 95\% Confidence Intervals; thin lines represent 90\% Confidence Intervals. All dependent variables are standardized. The models include actor-level and months-since-election fixed effects. Standard errors are clustered by actor.

of the radical right, the remaining politicians are able to compensate for the negativity that radical-right politicians bring to the debate.

\section{Qualitative analyses}

Afterwards, we provide evidence from qualitative analyses of a subsample of speeches in our data. If the results are indeed driven by a conscious strategy by MPs to distance themselves from the radical-right rhetoric, we should find evidence of that strategy by looking into the speeches in qualitative fashion. In these speeches, we indeed find examples of MPs calling out the negative, norm-breaching discourse of the radical right as 
Figure 5: Does the overall tone of the debate change? Differences in the use of positive and negative emotions as a function of distance to the state elections.

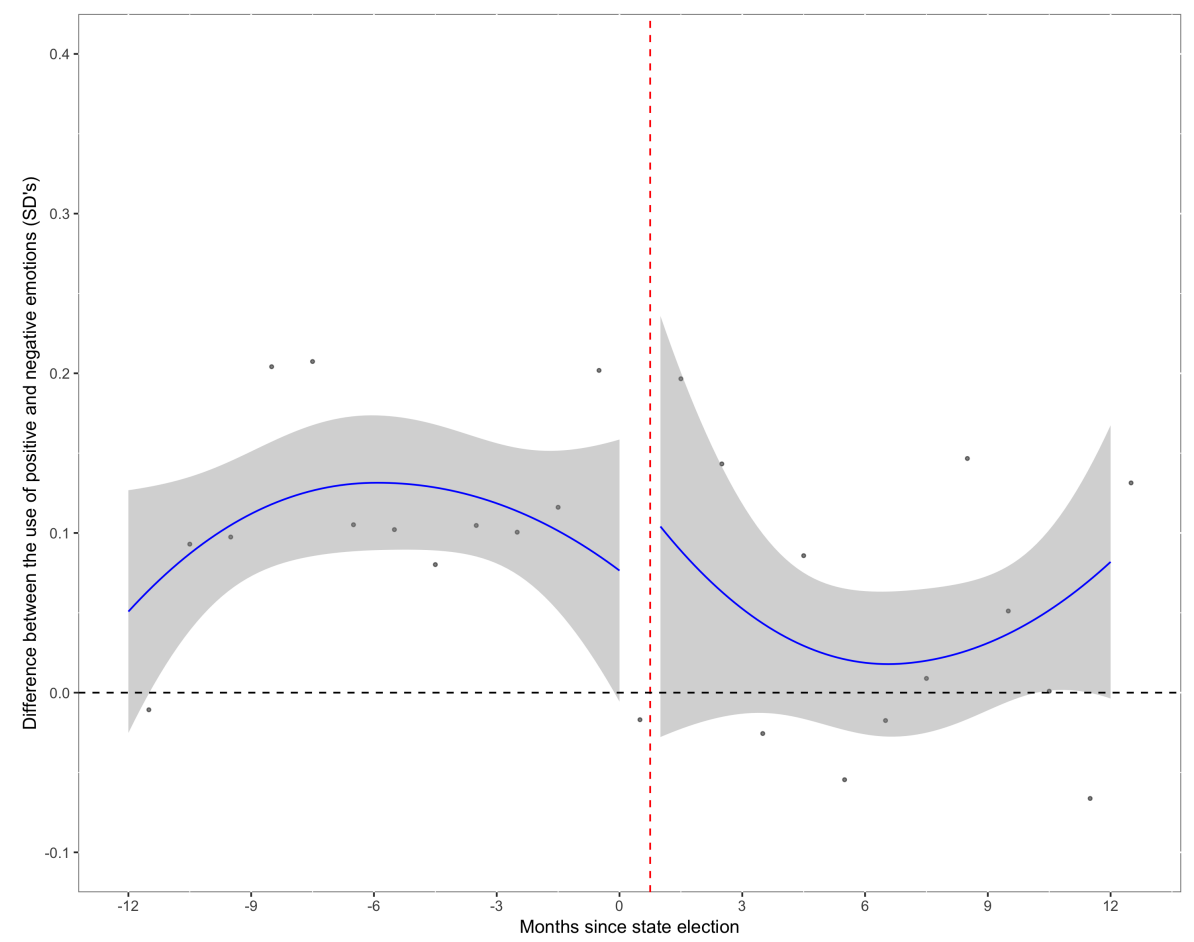

Notes: Dashed area represents 95\% Confidence Intervals. Values represent the difference in the values of PCA's for positive emotions and those of the PCA for positive emotions: higher values in this variable mean that the debate has an overall more positive tone; lower values in this variable mean that the debate has an overall more negative tone. Points represent local averages.

something new and unacceptable, that was detrimental to healthy democratic debate. For example, in her speech in November 30th 2016, Sabine Wölfe, MP for SPD (SocialDemocratic Party) in the state of Baden-Württemberg referred to negative rhetoric as characteristic of MPs of the AfD, and proceeded to call such rhetoric shocking: "Dear Madam President, ladies and gentlemen. That was a typical AfD speech: full of insults, off-topic and with the usual claims of world conspiracy from social networks. One is so shocked that one is speechless." 8

This calling out of the style of the negative discourse of the radical right suggests that the remaining politicians are aware of how it breaches established norms regulating the political debate. In calling it out on its norm-breaching nature, the remaining politicians

\footnotetext{
${ }^{8}$ To economize space, in the main text we provide only one example of each of the main patterns we find in the speeches. Appendix E provides some additional examples.
} 
may provide a signal that they will not follow course, and instead, support the norms in place.

This is further supported by the fact that, in calling out the negative discourse of the radical right as unacceptable, the remaining politicians often build a stark contrast between such discourse and that of their own party. In so doing, they often present themselves as the enforcers of the norms that this discourse breaches, claiming that they will fight to keep such norms from eroding. One such example can be found in the speech by Uwe Schwarz, MP for the SPD in Niedersachsen, in December 11 2018: "They [AfD MPs] deliberately stir up discord and envy in the hope of being able to catch voices. You can be sure that you will not succeed. It will find the bitter resistance of all democratic groups and factions in this house. We, the SPD, will be at the forefront."

This contrast between the radical-right politicians, breaching established norms, and one's own party is often accomplished by using emotional appeals. MPs frequently use positive emotions to distance themselves from the negative rhetoric of the radical right and use positive emotions to that end. The speech by Jan Christoph Oetjen, MP for the FDP in Niedersachsen, in March 17 2016, presents a clear example of this. The speech starts with a fearful tone, connecting negative emotions to the success of the radical right: "Germany is not immune to right-wing populists. The local elections in Hesse, for example, have now shown this. I fear that next weekend's elections will also show this, ladies and gentlemen. There is really nothing special about that either. Other countries in Europe have parties that get $15 \%$ or something similar that live with it. In our own country, this is a phenomenon that has only recently come into being, because a debate along these lines has developed in recent months and a mood has arisen among the population, which I believe Mrs Lorberg has taken up and misused for her political aims by people-jackers. As Mr Höntsch said earlier, the transition to violence is in part fluid. That worries me." Afterwards, however, the tone becomes positive as the politician marks the difference between himself and his party and the radical right: "That is why we in this House, all democrats together, must take great care to distinguish ourselves 
on the one hand from those who spread such slogans, but on the other hand to deal with their issues or arguments. We must seek to engage with those who argue against foreigners and right-wing populists. That is the point, ladies and gentlemen. That is why it was such a fatal signal in Rhineland-Palatinate that the Prime Minister said: No, if the AfD is taking part in the debate, then I am not coming. That is precisely wrong! Go into the debate, seek a debate, expose it, make arguments! That is the path that we as democrats must take together against the right-wing populists."

Reinforcing the idea that the use of positive emotions is strategic, we also find instances of politicians explicitly calling for voters to mobilize against the norm-breaching rhetoric of the radical-right - and using positive emotions to do so. One such example is found in the speech by Henning Homann, MP for the SPD in Sachsen, in February 29 2016: "The conclusion that we must draw from this is that we must get the commitment to democracy and openness to the world out of its niche. It must not just be the concern of a few. We must mobilise the silent and perhaps sometimes somewhat hesitant majority in this country. We must mobilise them to stand up for democracy. Because the point of democracy is that politics is not made for a few, but for the majority. That is why it must also be our demand that the majority stand up for democracy and not just a few; because it is in their own interest." This finding is in line with the quantitative finding that the emotions whose use increases the most after the radical right enters parliament are hope and enthusiasm - two emotions that are used to mobilize voters. Both findings suggest that the increased use of positive emotions to build a contrast toward the radical right is part of a strategy to mobilize voters against the norm-breaching rhetoric of the radical-right.

The anecdotal evidence discussed thus far suggests that the remaining politicians respond to radical-right success by using positive emotions as a ways of distancing themselves from the radical-right rhetoric and calling it out as unacceptable, which allows them to present themselves as the guardians of democratic norms that are breached by radical-right politicians. The use of positive emotions is thus instrumental in marking 
this contrast between one's way of doing politics and that of the radical right.

To check whether these anecdotes represent a larger pattern in our data, we conduct a more systematic qualitative analyses. Since our results show an increased use of positive emotions as a consequence of radical-right success, we start with taking the pool of speeches in our data that have a very high level of each of the positive emotions - values above twice the mean of each emotion-, from the post-election period, by politicians who are not from the AfD but which and which refer to AfD. From this pool, we randomly choose a subsample of 400. After removing speeches from members of state government, as in our main analyses, we end up with a total of 361 speeches that we then subject to thematic analysis (Boyatzis 1998). Following a deductive approach, in each speech we manually code whether the speaker reacts to radical-right success and rhetoric in the ways outlined in the anecdotes above, and which are relevant to our argument: reacting to radical-right success and rhetoric by calling out their general style of doing politics; by calling out their debating style in parliament specifically; and by building a contrast between the style of radical-right politicians and that of the speaker's party. Within each of these three categories, we also code the reason why MPs react to the radical right in this way. These are provided in the Appendix . To put these values into perspective, we also code reactions that criticize radical-right policy instead of their rhetoric. In so doing, we hope to have a baseline against which to compare our values.

Table 2: Frequency of reactions to the success and rhetoric of AfD politicians.

\begin{tabular}{crrr}
\hline \hline Category & Description & Absolute frequency & Proportion \\
\hline Criticizing general style & MPs call out the general way AfD MPs do politics as unnacceptable & 168 & 0.47 \\
Criticizing debating style & MPs call out the debating syle of AfD politicians as unnacceptable & 105 & 0.29 \\
Building contrast & MPs draw a clear opposition between their party's actions and those of AfD politicians & 144 & 0.40 \\
Criticizing policy & MPs disagree with policies being proposed by AfD & 0.26 \\
\hline
\end{tabular}

Table 2 shows the results of these analyses. It shows that the more frequent reaction among these four is to call out the general political style of the AfD as unacceptable - a reaction which we find in almost half the speeches analysed. This is followed by the building of a contrast between AfD politicians and the speaker and her party - which 
we find in $40 \%$ of the speeches analysed. As detailed in Appendix , the main ways by which politicians mark involve the use of positive emotions. Calling out of the debating style of AfD's politicians in parliament is a reaction found in $29 \%$ of the speeches. These proportions are quite impressive, considering that we only find criticism of policy - which should happen quite often in parliamentary debates - in $26 \%$ of the speeches analysed. These analyses suggest that the anecdotal evidence presented above seems to represent a broader pattern in the data: politicians react to radical-right success by increasing the use of positive emotions as a ways of distancing themselves from the radical-right discourse, which they call out as unacceptable. In so doing, they get to present themselves as the enforcers of the norms breached by the radical-right discourse, and to mobilize voters to stand up against this norm-breaching rhetoric.

\section{Alternative mechanism: Are the effects driven by a change in the issues that are debated?}

Finally, we test for an alternative mechanism. It might be that the change in emotionality of the debate is a consequence of a change in the issues that are debated in state parliaments. If mainstream politicians attach different sets of emotions to different topics, the parliamentary entry of radical-right MPs could change the level of emotionality simply by increasing the frequency of discussion of issues that the remaining politicians are very positive about. Should this be the case, conditioning on how often radical-right politicians discuss a given issue, one should find no effect on the use of positive emotions. Rather, the effect should be driven simply by the fact that radical-right politicians discuss some issues more often than others.

In order to test this alternative mechanism, we need data on the main topic of each speech, and on the relative salience of each topic across time. We do so with resource to topic modelling, a text analysis method that belongs to the family of "unsupervised" tools. Topic models recognize repeating patterns of co-occurring words in a text corpus 
and order them into distinct concepts, which can then be interpreted as topics (Grimmer and Stewart 2013). In order to identify topics of speeches in our text corpus, we rely on a specific topic model algorithm: structural topic models (STM) (Roberts, Stewart, and Tingley 2014). STM allows for the possibility of incorporating metadata, defined as additional information about each document. We are thus able to base the estimation of topic proportions on a number of different covariates. Since we assume that topic salience is strongly influenced by the political party of the speakers, we included the party variable as a topical prevalence factor. Furthermore, we assume that topic salience is a function of time, thus, adding the date variable as another topical prevalence factor. For further specifications and pre-processing steps of the topic model please see the Online Appendix D.

We identified the following 22 topics: police and security; alternative energy, agriculture, and environment; research and university; parliamentary investigation; animals and animal protection; transportation; refugees and asylum; school and education; legislation and law; European Union; budget; volunteering, sports, and integration; gender equality; labor market and housing; public broadcasting and media; rural areas and economy; family and children; data privacy and crime; health; extremism, racism, and Islam; procedural; and federalism. Table D.2 in Appendix D of the Online Appendix shows the full list of all topics along with their respective FREX terms - i.e., words that are frequently appearing in one topic and less frequently in all others. Among these topics, we assign the one with the highest $\theta$ value, which represents the probability of a topic given a document, to each speech. ${ }^{9}$

We can now look at whether there are differences in the level of emotionality of MPs as a consequence of radical-right success, conditional on how important the issue is for the radical right. To do so, we start with looking at the proportion of the total number of radical-right speeches that draw upon each specific issue. Then, we split our sample into two subsamples: one subsample including the eleven topics that the radical

\footnotetext{
${ }^{9}$ Each document receives $k$ topic proportions, which in total add up to a value of one. The highest theta value represents the highest likelihood that a document is related to the respective topic.
} 
right discusses most often; ${ }^{10}$ and one subsample including the eleven topics that the radical right discusses least often. ${ }^{11}$ Then, we replicate the main analyses in these two subsamples.

Figure 6: Effects conditional on how often radical right MPs debate the topic of the speech.

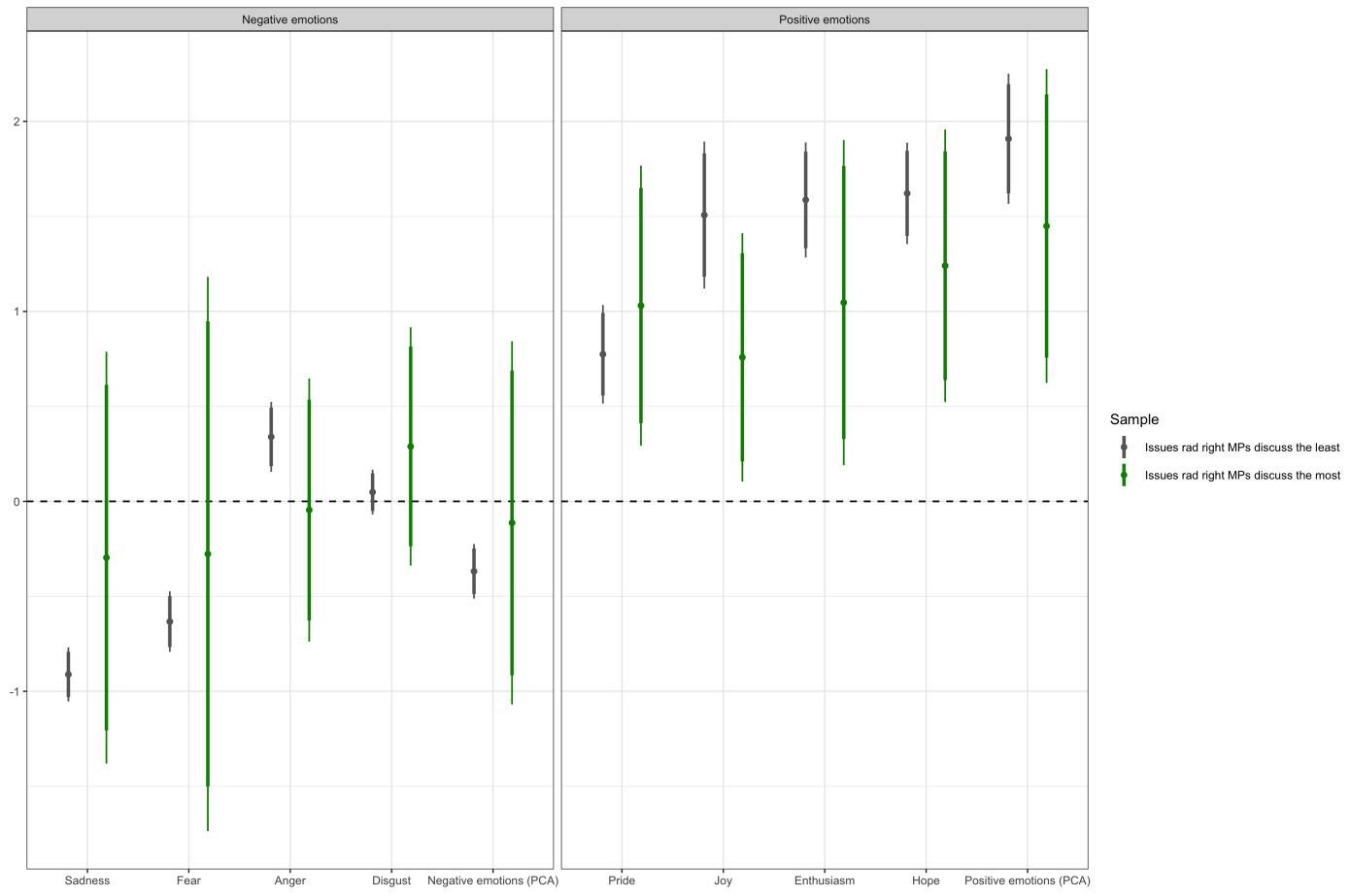

Notes: Thick lines represent 95\% Confidence Intervals; thin lines represent $90 \%$ Confidence Intervals. All dependent variables are standardized. The models include actor-level and months-since-election fixed effects. Standard errors are clustered by actor.

Figure 6 shows the results of these analyses. The evidence suggests that the results are not being driven simply by radical-right politicians giving more importance to issues regarding which the remaining politicians are more positive. While the effects seem slightly stronger on issues that radical-right politicians discuss least often, we find a clear increase in the use of positive emotions by the remaining politicians in both subsamples.

\footnotetext{
${ }^{10}$ These issues are alternative energy, agriculture, and environment; budget; European Union; extremism, racism, and Islam; legislation and law; transportation; labor market and housing; procedural; refugees and asylum; school and education; and police and security.

${ }^{11}$ These issues are research and university; parliamentary investigation; animals and animal protection; volunteering, sports, and integration; gender equality; public broadcasting and media; rural areas and economy; family and children; data privacy and crime; health; and federalism.
} 


\section{Conclusion}

The way mainstream parties and politicians react to the strategy of their niche challengers is what makes or breaks the success of such strategy (Meguid 2005). Existing literature has provided extensive evidence that, when it comes to policy positions, mainstream politicians tend to react to the threat posed by radical-right contenders by coming closer to their position. Using newly collected data on speeches in German state parliaments and an original emotional dictionary, we found that this is not the case when it comes to the tone of the discourse. While the rhetoric of radical-right politicians is characterized by extensive use of negative emotions, their success has no effect on the use of negative emotions by the remaining politicians. In turn, radical-right success increases the use of positive emotions (hope, enthusiasm, joy, and pride) by the remaining politicians.

We have argued that this increasingly positive rhetoric may be driven by a strategic decision by the remaining politicians to distance themselves from the negativity that the radical right brings to the debate. Doing so allows mainstream politicians to present themselves as the guardians of the democratic norms that radical-right politicians breach; and it can serve as a way to tone down the negativity of the debate that can further fuel the electoral success of the radical right. A mix of quantitative and qualitative analyses pays support to this argument. They suggest that the increasing use of positive emotions is a means by which politicians create a contrast between the radical right, breaching established norms, and themselves, enforcers of those norms. In so doing, they seem to attempt to mobilize voters on the basis of opposition to the negativity that the radical right brings to the debate. Finally, our data suggest that this increasing use of positive emotions effectively counterbalances the negativity that radical-right success brings to

the debate, keeping the overall tone of the political debate from becoming significantly more negative.

On the one hand, this conclusion is at odds with previous research showing that mainstream politicians react to radical-right success by adopting increasingly rightist policy 
positions. One possible explanation for this difference is that mainstream politicians follow different strategies in different dimensions of their electoral appeal. They may adopt increasingly rightist policy positions as a ways of trying to appeal to radical-right voters; and, at the same time, call out their negative rhetoric as unacceptable to try and keep their traditional constituencies. This can represent a strategy of "parroting the pariah", whereby established politicians come closer to the positions of extremist contenders but ostracize them at the same time (Van Spanje and Graaf 2018).

On the other hand, our findings are in line with previous research in highlighting how politicians tend to use emotions strategically (Crabtree et al. 2018). However, our paper adds an important insight to this conclusion. As our findings suggest, the emotional appeals used by different politicians change depending on who their challengers are and how electorally successful they become. Concretely, the success of candidates whose rhetoric is deemed unacceptable increases the incentives to use emotions as a tool to mobilize voters against such rhetoric. Our findings also support and provide further detail to previous research showing that the success of radical-right candidates can have a polarizing effect (Bischof and Wagner 2019). While this research has focused on the effect of radical-right success on voters, we find a similar effect on the rhetorical style of political elites.

One question raised by this conclusion is to what extent these findings are likely to travel beyond the German case. On the one hand, previous research has shown that democracies tend to create norms against parties with affinities to previous dictatorships (Dinas and Northmore-Ball 2019; Dinas, Martínez, and Valentim 2020). This is even more likely in Germany, given the particularly devastating consequences of the Nazi regime the country witnessed. The creation of strong norms against rhetoric associated with radical-right politicians might force established politicians to respond to their success with clear differentiation. This being said, we believe the findings are not simply a product of the specific characteristics of the German case. Radical-right politicians have been increasingly successful across most advanced democracies, and the set of incentives 
for discursive differentiation that such success generates are likely to apply elsewhere. Anecdotally, one can find examples of this strategy in other contexts as well. In Spain, the incumbent party PSOE reacted to the successful radical-right Vox by stressing its leftist position and the party's role in the Spanish transition to democracy (De Vries and Hobolt 2020, pp. 250-251). Similar examples can be found even in countries without an authoritarian past. During the US Presidential Campaign of 2016, Hillary Clinton refused time and time again to give in to the negative rhetoric of Donald Trump which, like in our data, she called out as unacceptable (Lerner 2015).

Overall, our results highlight how electoral competition can push mainstream politicians to present themselves as guardians of democratic norms that radical-right politicians breach. Radical-right rhetoric is in many ways damaging to democracy, in their perpetuation of stereotypes about minority groups, spread of fake news, or negative discourse. Nevertheless, our results suggest that their success can create incentives for other politicians to distance themselves from negativity of radical-right rhetoric, which can mitigate part of these negative consequences. Given that negative debating has been associated with detrimental outcomes such as affective polarization (Iyengar, Sood, and Lelkes 2012), this finding carries important implications for the quality of democracy. In increasing the use of positive instead of negative emotions, mainstream politicians do not feed potential loops of negativity that could be very detrimental to the process of public deliberation. 


\section{References}

Abou-Chadi, Tarik. 2016. "Niche party success and mainstream party policy shifts-how green and radical right parties differ in their impact". British Journal of Political Science 46 (2): 417-436.

Abou-Chadi, Tarik, and Werner Krause. 2018. "The Causal Effect of Radical Right Success on Mainstream Parties' Policy Positions: A Regression Discontinuity Approach". British Journal of Political Science: 1-19.

Abou-Chadi, Tarik, and Matthias Orlowski. 2016. "Moderate as necessary: the role of electoral competitiveness and party size in explaining parties' policy shifts". Publisher: University of Chicago Press Chicago, IL, The Journal of Politics 78 (3): 868-881.

Ansolabehere, Stephen, Shanto Iyengar, Adam Simon, and Nicholas Valentino. 1994. "Does attack advertising demobilize the electorate?" Publisher: Cambridge University Press, American Political Science Review 88 (4): 829-838.

Arzheimer, Kai, and Carl C. Berning. 2019. "How the Alternative for Germany (AfD) and their voters veered to the radical right, 2013-2017". Electoral Studies 60:102040.

Bale, Tim. 2003. "Cinderella and her ugly sisters: the mainstream and extreme right in Europe's bipolarising party systems". West European Politics 26 (3): 67-90.

Benoit, Kenneth, Drew Conway, Benjamin E. Lauderdale, Michael Laver, and Slava Mikhaylov. 2016. "Crowd-sourced text analysis: Reproducible and agile production of political data". Publisher: Cambridge University Press, American Political Science Review 110 (2): 278-295.

Berinsky, Adam J., Michele F. Margolis, and Michael W. Sances. 2014. "Separating the shirkers from the workers? Making sure respondents pay attention on self-administered surveys". Publisher: Wiley Online Library, American Journal of Political Science 58 (3): 739-753.

Bernick, E. Lee, and Charles W. Wiggins. 1983. "Legislative Norms in Eleven States". Publisher: [Wiley, Comparative Legislative Research Center], Legislative Studies Quarterly 8 (2): 191-200.

Bicchieri, Cristina, and Erte Xiao. 2009. "Do the right thing: but only if others do so". Journal of Behavioral Decision Making 22 (2): 191-208.

Bischof, Daniel, and Markus Wagner. 2019. "Do Voters Polarize When Radical Parties Enter Parliament?" American Journal of Political Science 63 (4): 888-904.

Boyatzis, Richard E. 1998. Transforming qualitative information: Thematic analysis and code development. sage.

Brader, Ted. 2005. "Striking a responsive chord: How political ads motivate and persuade voters by appealing to emotions". Publisher: Wiley Online Library, American Journal of Political Science 49 (2): 388-405.

Brader, Ted, and George E. Marcus. 2013. "Emotion and political psychology." In The Oxford Handbook of Political Psychology, ed. by Leonie Huddy, David O. Sears, and Jack S. Levy. Publisher: Oxford University Press. 
Brader, Ted, Nicholas A. Valentino, and Elizabeth Suhay. 2008. "What triggers public opposition to immigration? Anxiety, group cues, and immigration threat". Publisher: Wiley Online Library, American Journal of Political Science 52 (4): 959-978.

Broockman, David E, Joshua L Kalla, and Jasjeet S Sekhon. 2017. "The design of field experiments with survey outcomes: A framework for selecting more efficient, robust, and ethical designs". Political Analysis 25 (4): 435-464.

Bursztyn, Leonardo, Georgy Egorov, and Stefano Fiorin. 2017. From extreme to mainstream: How social norms unravel. Tech. rep. National Bureau of Economic Research.

Bustikova, Lenka. 2014. "Revenge of the Radical Right, Revenge of the Radical Right". Comparative Political Studies 47 (12): 1738-1765.

Carter, Neil. 2013. "Greening the mainstream: party politics and the environment". Publisher: Routledge, Environmental Politics 22 (1): 73-94.

Ceccobelli, Diego. 2018. "Not every day is Election Day: a comparative analysis of eighteen election campaigns on Facebook". Journal of Information Technology \& Politics 15 (2): $122-141$.

Chavez, Leo R., Belinda Campos, Karina Corona, Daina Sanchez, and Catherine Belyeu Ruiz. 2019. "Words hurt: Political rhetoric, emotions/affect, and psychological wellbeing among Mexican-origin youth". Social Science \&6 Medicine 228:240-251.

Crabtree, Charles, Matt Golder, Thomas Gschwend, and Indridi Indridason. 2018. "It's Not Only What You Say, It's Also How You Say It: The Strategic Use of Campaign Sentiment".

De Vries, Catherine E., and Sara Hobolt. 2020. Political entrepreneurs: the rise of challenger parties in Europe. Princeton, NJ: Princeton University Press.

De Vries, Catherine E., and Sara B. Hobolt. 2012. "When dimensions collide: The electoral success of issue entrepreneurs". European Union Politics 13 (2): 246-268.

Dinas, E., and F. Foos. 2017. "The national effects of subnational representation: Access to regional parliaments and national electoral performance". Quarterly Journal of Political Science 12 (1): 1-35.

Dinas, Elias, and Kostas Gemenis. 2010. "Measuring Parties' Ideological Positions With Manifesto Data: A Critical Evaluation of the Competing Methods". Publisher: SAGE Publications Ltd, Party Politics 16 (4): 427-450.

Dinas, Elias, Sergi Martínez, and Vicente Valentim. 2020. Issue Salience and Norm Change in New Democracies. SSRN Scholarly Paper ID 3516831. Rochester, NY: Social Science Research Network.

Dinas, Elias, and Ksenia Northmore-Ball. 2019. "The Ideological Shadow of Authoritarianism". Comparative Political Studies: 0010414019852699.

Dinas, Elias, Pedro Riera, and Nasos Roussias. 2015. "Staying in the first league: Parliamentary representation and the electoral success of small parties". Political Science Research and Methods 3 (2): 187-204.

Franceschet, Susan. 2010. "The gendered dimensions of rituals, rules and norms in the Chilean Congress". Publisher: Taylor \& Francis, The Journal of Legislative Studies 16 (3): 394-407. 
Gadarian, Shana Kushner, and Bethany Albertson. 2014. "Anxiety, immigration, and the search for information". Publisher: Wiley Online Library, Political Psychology 35 (2): $133-164$.

Grimmer, Justin, and Brandon M. Stewart. 2013. "Text as data: The promise and pitfalls of automatic content analysis methods for political texts". Publisher: Cambridge University Press, Political analysis 21 (3): 267-297.

Grzesiak-Feldman, Monika. 2013. "The effect of high-anxiety situations on conspiracy thinking". Publisher: Springer, Current Psychology 32 (1): 100-118.

Han, Kyung Joon. 2015. "The impact of radical right-wing parties on the positions of mainstream parties regarding multiculturalism". West European Politics 38 (3): 557576.

Hobbs, William, and Nazita Lajevardi. 2019. "Effects of Divisive Political Campaigns on the Day-to-Day Segregation of Arab and Muslim Americans". American Political Science Review 113 (1): 270-276.

Hobolt, Sara B., and Catherine E. De Vries. 2015. "Issue Entrepreneurship and Multiparty Competition". Comparative Political Studies 48 (9): 1159-1185.

Huitt, Ralph K. 1957. "The Morse committee assignment controversy: a study in Senate norms". Publisher: JSTOR, The American Political Science Review 51 (2): 313-329.

Iyengar, Shanto, Gaurav Sood, and Yphtach Lelkes. 2012. "Affect, not ideology: Social identity perspective on polarization". Publisher: Oxford University Press, Public opinion quarterly 76 (3): 405-431.

Jewett, Aubrey. 2002. "Evaluating Changes in Florida's Legislative Process: Innovative Rules and Conservative Norms". Politics \& Policy 30 (1): 40-68.

Just, Marion R., Ann N. Crigler, and Todd L. Belt. 2007. "Don't give up hope: Emotions, candidate appraisals, and votes." In The Affect Effect: Dynamics of Emotion in Political Thinking and Behavior, ed. by W. Russell Neuman, George E. Marcus, Ann N. Crigler, and Michael MacKuen. Google-Books-ID: VyAvdCY7qhMC. University of Chicago Press.

Kühne, Rinaldo, and Christian Schemer. 2015. "The emotional effects of news frames on information processing and opinion formation". Publisher: Sage Publications Sage CA: Los Angeles, CA, Communication Research 42 (3): 387-407.

Lau, Richard R., and Gerald M. Pomper. 2001. "Effects of negative campaigning on turnout in US Senate elections, 1988-1998". Journal of Politics 63 (3).

Lehmann, Pola, and Malisa Zobel. 2018. "Positions and saliency of immigration in party manifestos: A novel dataset using crowd coding". Publisher: Wiley Online Library, European Journal of Political Research 57 (4): 1056-1083.

Lerner, Adam B. 2015. Hillary Clinton: Donald Trump's racial rhetoric 'not acceptable'. Library Catalog: www.politico.com.

Mayntz, Renate. 1992. "Social norms in the institutional culture of the German Federal Parliament". Publisher: University of California Press, Theory of Culture: 219-240. 
Meguid, Bonnie M. 2005. "Competition between unequals: The role of mainstream party strategy in niche party success". American Political Science Review 99 (3): 347-359.

Meier, Tabea, Ryan L. Boyd, James W. Pennebaker, Matthias R. Mehl, Mike Martin, Markus Wolf, and Andrea B. Horn. 2019. "“LIWC auf Deutsch": The Development, Psychometrics, and Introduction of DE-LIWC2015". Publisher: University of Zurich, PsyArXiv, no. a.

Mikolov, Tomas, Kai Chen, Greg Corrado, and Jeffrey Dean. 2013. "Efficient Estimation of Word Representations in Vector Space". arXiv:1301.3781 [cs]. arXiv: 1301.3781.

Mohammad, Saif M., and Peter D. Turney. 2010. "Emotions evoked by common words and phrases: Using mechanical turk to create an emotion lexicon". In Proceedings of the NAACL HLT 2010 workshop on computational approaches to analysis and generation of emotion in text, 26-34. Association for Computational Linguistics.

Mudde, Cas. 2004. "The populist zeitgeist". Government and Opposition 39 (4): 542-563.

Pattie, Charles, David Denver, Robert Johns, and James Mitchell. 2011. "Raising the tone? The impact of 'positive'and 'negative'campaigning on voting in the 2007 Scottish Parliament election". Publisher: Elsevier, Electoral Studies 30 (2): 333-343.

Pennebaker, James W., Matthias R. Mehl, and Kate G. Niederhoffer. 2003. "Psychological Aspects of Natural Language Use: Our Words, Our Selves". Annual Review of Psychology 54 (1): 547-577.

Proksch, Sven-Oliver, and Jonathan B. Slapin. 2012. "Institutional foundations of legislative speech". Publisher: Wiley Online Library, American Journal of Political Science $56(3): 520-537$.

Rauh, Christian. 2018. "Validating a sentiment dictionary for German political language - a workbench note". Publisher: Taylor \& Francis, Journal of Information Technology \& Politics 15 (4): 319-343.

Rico, Guillem, Marc Guinjoan, and Eva Anduiza. 2017. "The emotional underpinnings of populism: How anger and fear affect populist attitudes". Publisher: Wiley Online Library, Swiss Political Science Review 23 (4): 444-461.

Roberts, Margaret E., Brandon M. Stewart, and Dustin Tingley. 2014. "stm: R package for structural topic models". Journal of Statistical Software 10 (2): 1-40.

Rudkowsky, Elena, Martin Haselmayer, Matthias Wastian, Marcelo Jenny, Štefan Emrich, and Michael Sedlmair. 2018. "More than bags of words: Sentiment analysis with word embeddings". Publisher: Taylor \& Francis, Communication Methods and Measures 12 (2-3): 140-157.

Rush, Michael, and Philip Giddings. 2011. Parliamentary socialisation. Springer.

Sagarzazu, Iñaki, and Heike Klüver. 2017. "Where Have All the Leaders Gone? Evaluating the Dynamics of Parties' Issue Attention in Coalition Governments". _eprint: https://onlinelibrary.wiley.com/doi/pdf/10.1111/ssqu.12437, Social Science Quarterly 98 (3): 1045-1060.

Schain, Indirect Effects Martin A. 2006. "The extreme-right and immigration policymaking: Measuring direct and indirect effects". West European Politics 29 (2): 270289. 
Somer-Topcu, Zeynep. 2009. "Timely decisions: The effects of past national elections on party policy change". Publisher: Cambridge University Press New York, USA, The Journal of Politics 71 (1): 238-248.

Tausczik, Yla R., and James W. Pennebaker. 2010. "The psychological meaning of words: LIWC and computerized text analysis methods". Publisher: Sage Publications Sage CA: Los Angeles, CA, Journal of language and social psychology 29 (1): 24-54.

Valentim, Vicente. 2018. Parliamentary Representation and the Normalization of Radical Right Support. SSRN Scholarly Paper ID 3289275. Rochester, NY: Social Science Research Network.

Valentino, Nicholas A., Ted Brader, Eric W. Groenendyk, Krysha Gregorowicz, and Vincent L. Hutchings. 2011. "Election night's alright for fighting: The role of emotions in political participation". Publisher: Cambridge University Press New York, USA, The Journal of Politics 73 (1): 156-170.

Valentino, Nicholas A., Vincent L. Hutchings, Antoine J. Banks, and Anne K. Davis. 2008. "Is a worried citizen a good citizen? Emotions, political information seeking, and learning via the internet". Publisher: Wiley Online Library, Political Psychology 29 (2): 247-273.

Van Spanje, Joost, and Nan Dirk de Graaf. 2018. "How established parties reduce other parties' electoral support: the strategy of parroting the pariah". Publisher: Taylor \& Francis, West european politics 41 (1): 1-27.

Vasilopoulos, Pavlos, George E. Marcus, and Martial Foucault. 2018. "Emotional responses to the Charlie Hebdo attacks: Addressing the authoritarianism puzzle". Publisher: Wiley Online Library, Political Psychology 39 (3): 557-575.

Vasilopoulos, Pavlos, George E. Marcus, Nicholas A. Valentino, and Martial Foucault. 2019. "Fear, anger, and voting for the far right: Evidence from the November 13, 2015 Paris terror attacks". Publisher: Wiley Online Library, Political Psychology 40 (4): 679-704.

Vasilopoulou, Sofia, and Markus Wagner. 2017. "Fear, anger and enthusiasm about the European Union: Effects of emotional reactions on public preferences towards European integration". Publisher: SAGE Publications Sage UK: London, England, European Union Politics 18 (3): 382-405.

Widmann, Tobias. 2019. How Emotional Are Populists Really? Factors Explaining Emotional Appeals in the Communication of Political Parties. SSRN Scholarly Paper ID 3590265. Rochester, NY: Social Science Research Network.

Young, Lori, and Stuart Soroka. 2012. "Affective news: The automated coding of sentiment in political texts". Publisher: Taylor \& Francis, Political Communication 29 (2): 205-231. 


\section{Online Appendix}

\section{Contents}

A Deviations from the pre-analysis plan 1

B Details on the original dictionary 1

$\begin{array}{ll}\text { C Examples of text scoring high on each emotion } & 8\end{array}$

C.1 Examples of speeches scoring high on anger . . . . . . . . . . 8

C.2 Examples of speeches scoring high on fear . . . . . . . . . . . 8

C.3 Examples of speeches scoring high on disgust . . . . . . . . . . . . 9

C.4 Examples of speeches scoring high on sadness . . . . . . . . . . . . 9

C.5 Examples of speeches scoring high on joy . . . . . . . . . . . . . 10

C.6 Examples of speeches scoring high on enthusiasm . . . . . . . . . . 11

C.7 Examples of speeches scoring high on pride . . . . . . . . . . . . 11

C.8 Examples of speeches scoring high on hope . . . . . . . . . . . . . 12

$\begin{array}{ll}\text { D Additional analyses } & 13\end{array}$

E Further speeches that illustrate the arguments made in the section on the mechanism.

F Further details on the qualitative analyses $\quad 23$ 


\section{A Deviations from the pre-analysis plan}

Our study deviates from the pre-analysis plan in two main ways, which we detail below.

1. Upon presenting the work to colleagues and receiving their feedback, we decided to change the name of the second hypothesis. In the pre-analysis plan, it was titled "differentiation hypothesis", while in the current version of the paper it reads "distancing hypothesis", which we think reflects better the argument we put forward.

2. All the analyses that intend to provide evidence on the mechanism at play were thought of after knowing what the main effect was. These analyses were meant as exploratory in nature, whose goal was to provide in-depth understanding of the mechanism driving the main effect. This includes the qualitative analyses and the subsample analyses reported in the section on the mechanism, as well as the rationale for the implications of the mechanism found in the theoretical section. This also means that the second part of our distancing hypothesis, which refers to how effects should differ across politicians of different parties, was thought of post-hoc. Our pre-analysis plan included only the two main hypothesis, with no mention to the subsample analyses. Upon receiving peer feedback, we decided that including all theoretical reasoning together, regardless of it being pre-registered or not, made for a better reading and understanding of the paper than to have two separate theoretical sections - one, pre-registered, for the main effect; one, not preregistered, for the mechanism and subsample analyses. We hope that this choice makes for a more straightforward understanding of the paper, without sacrificing transparency.

\section{B Details on the original dictionary}

This study applies a novel emotional dictionary ("ed8"), that has been specifically created to measure discrete emotional language in political text, while taking into consideration German language specifics. It is specifically tailored to the political context and capable of measuring language associated with a wide range of different positive and negative emotions. Furthermore, contrary to many off-the-shelf dictionaries, the ed 8 dictionary includes negation control. Similar to the augmented dictionary, the ed8 dictionary recognizes a variety of different negation patterns by including bigram negations, which are identified and replaced by markers in order for them not to be counted in the final emotional scores.

The dictionary has been created along a semi-automated two-step procedure. First, all terms have been manually reviewed and attributed, if suitable, into different emotional categories. From the total of 30,070 words included in the augmented dictionary, 19,091 terms have been categorized into one or more of the eight different emotional categories.

In a second step, we trained a word embeddings model using Google's word2vec algorithm implemented in the $\mathrm{R}$ package rword2vec. Word embeddings are a method to analyze and understand words and their meaning (Mikolov et al. 2013). These models 
take into account the context in which words appear. Words are represented as a position in a multidimensional space, and the use of each word is predicted based on its contiguous words. The algorithm then turns each word into numerical values, which can be used to calculate distances between terms. More similar words are closer to one another, words with different meanings are more distant. Thus, based on these numerical values it easy to find words with semantic similarity which then can be used to expand an already existing dictionary.

To do so, the algorithm was locally trained on a large corpus of German political text, including parliamentary speeches, press releases and social media data from political parties in Germany, Austria, and Switzerland. We then used words that have been already attributed to one of the eight emotional categories to find synonyms and other words that have not yet been included in the dictionary. In this manner, we added 1491 terms (including inflections) to the previously identified 19091 terms. The ed8 dictionary now consists of a total number of 20,582 terms, which are attributed to one or several emotional categories.

The individual lists for each emotional category have comparable sizes among emotions of the same valence, i.e. all negative emotions have approximately similar lengths and all positive emotions have approximately similar lengths. However, comparing negative categories to positive categories, lists for negative emotions are slightly longer. The list for anger includes 4,743 terms, for fear 4,024 terms, for disgust 4,216 terms, and for sadness 3,889 terms. The list for joy contains 2,800 terms, for enthusiasm 2,247 terms, for pride 3,063 terms, and for hope 2,526 terms. Thus, there is an overweight of negative words which, however, is closer to the real balance of positive and negative terms in German political language (see Rauh 2018).

As we refer in the main text, one of the reasons why we develop a new dictionary is to ensure its applicability to the German language. Many off-the-shelf dictionaries are tailored to the English language context and have been subsequently translated to other languages, often using automated machine-translation. This, however, makes them inept to process language specific grammar which in turn can lead to distorted results. To better illustrate this shortcoming of automatically translated dictionaries, we applied the German version of the "NRC Word-Emotion Association Lexicon" (EmoLex, see Mohammad and Turney 2010) - a widely used emotional language dictionary available in over hundred languages - to the very short example sentence containing language with clear use of negative emotions.

Table B.1: Results of coding an example sentence using the NRC EmoLex dictionary.

Example: "Ich hasse die Regierung und diese ganzen Idioten!" ("I hate the government and all these idiots!")

\begin{tabular}{cccccccccc}
\hline Anger & Anticipation & Disgust & Fear & Joy & Sadness & Surprise & Trust & Negative & Positive \\
0 & 0 & 0 & 0 & 0 & 0 & 0 & 0 & 0 & 0
\end{tabular}

As Table B.1 shows, the EmoLex dictionary does not capture any of the clearly negative words in the sentence. While the infinitive form of hate and the singular form of idiot are included in the German version of the EmoLex, the first-person conjugation "hasse" (instead of "hassen", to hate) and the plural form "Idioten" are not. As shown in Table B.2, the novel emotional dictionary applied in this study ("ed8") computes following output, which clearly shows the negatively charged language in the example sentence. 
Table B.2: Results of coding an example sentence using the ed8 dictionary.

Example: "Ich hasse die Regierung und diese ganzen Idioten!"

("I hate the government and all these idiots!")

\begin{tabular}{cccccccc}
\hline Anger & Fear & Disgust & Sadness & Joy & Enthusiasm & Pride & Hope \\
2 & 1 & 1 & 1 & 0 & 0 & 0 & 0
\end{tabular}

To validate the dictionary at hand, we have chosen crowd sourcing (or crowd coding) which is one of state-of-the-art methods used to code text in the social sciences (Benoit et al. 2016; Lehmann and Zobel 2018). Crowd sourcing refers to using the internet to distribute large amounts of small tasks to a very high number of workers around the world that receive financial rewards per task. Harvesting "the wisdom of crowds" offers new possibilities for researchers who want to quickly code large sections of political texts. It is very similar to manual coding, yet it is faster because several workers can work on the tasks simultaneously. However, one crucial difference is that crowd coders are no experts in the topic at hand. Instead, crowd coding is based on the assumption that judgement of many individuals taken together will eventually lead to a "true" answer (Benoit et al. 2016).

To conduct the validation process, we used a German crowd working platform called Crowdguru, which is similar to Amazon's Mechanical Turk. While our study focuses on parliamentary speeches, we want to make sure that the validity of our dictionary travels beyond this specific data source. As such, following Rauh (Rauh 2018), we use data from different sources of political communication. Concretely, we selected 10,000 sentences coming from parliamentary speeches - drawn from the current legislative period of the German Bundestag, between October 2017 and June 2019 - and Facebook posts taken from the official Facebook accounts of all German parties, during the same period ${ }^{12}$. The speeches and Facebook posts were subsequently collapsed into sentences, resulting in a total of 333,572 sentences in parliamentary speeches and 34,375 sentences in Facebook posts. From these sentences, 20 percent of the validation data (2000 sentences) were randomly selected. The remaining 80 percent were selected from pre-sampled data sets. Research on emotional language shows that emotional words only rarely occur in communication (Pennebaker, Mehl, and Niederhoffer 2003). Thus, randomly selecting sentences from the overall sample would most likely lead to a very low amount of emotionality, which would mean that from the 10,000 sentences only a few hundred sentences would include emotional language. Hence, we applied the ed8 dictionary to the overall sample of sentences and subsequently pre-sampled data sets for each emotion, including only sentences that have an emotional score above 0 for the respective emotion. This resulted in eight data sets (one for each emotion) with sentences that have an emotional score that is greater than 0 . From each of these eight pre-sampled data sets we subsequently selected 10 percent (1000 sentences) of the validation sample, resulting in 8000 sentences. Taken together with the 2000 sentences that were randomly chosen, this results in the

\footnotetext{
${ }^{12}$ While a replication of the main analyses of the paper on social media data would be interesting, it is unfortunately not possible because many state-level politicians could not be found in social media. Among the ones we could trace, many do not have a professional account, and their social media accounts (which have a very limited number of followers) include mostly posts about their daily life that have no connection to the political debate.
} 
total validation sample of 10,000 sentences.

To ensure valid and reliable data production, it is essential to build in several quality control measures. Similar to recent studies using crowd coding for data production (Benoit et al. 2016; Lehmann and Zobel 2018; Rudkowsky et al. 2018), the validation process included different tests before and during the coding process to assure a high quality of coding (see Online Appendix B for details). First, coders had to finish a start quiz consisting of so-called "gold sentences". Gold sentences are sentences that are clearly associated with one specific emotion and therefore have a predefined unambiguous answer (Benoit et al. 2016). We used "artificially" constructed gold sentences to be able to manipulate the emotional strength. If the coder does not choose the predefined answer, the answer is counted as incorrect. In the start quiz, 80 percent of the answers had to be answered correctly in order to be admitted to the job. Ten crowd workers did not pass the start quiz and hence were not allowed to work on the task. During the coding process, the quality of the coders was assured using either gold sentences or "screeners". Screener sentences contain an exact instruction on how to label the sentence, which are designed to assure that coders carefully read the sentences (Berinsky, Margolis, and Sances 2014). Based on the answers to the randomly chosen test question (gold sentence or screener) in each HIT, trust scores were calculated for each individual coder in regular intervals. Coders whose trust score fell below 60 percent were ejected from the job and their assignments added back to the HIT pool. However, only one crowd worker fell below the threshold of 60 percent and was subsequently removed from the task.

The crowd coded sentences serve as "true" answers and allow us to measure the accuracy of the ed 8 dictionary. To do so, we calculate precision, recall, and F1 scores. Recall is the ratio of correctly predicted observations to the total amount of true observations. Recall scores therefore give the ratio of sentences correctly judged as "emotional" (e.g. angry) by the dictionary to the total amount of sentences judged as "emotional" (e.g. angry) by the human coders. Precision, on the other hand, is the ratio of correctly predicted observations to the total predicted observations. This means that precision is the ratio of correctly judged sentences by the dictionary to the total amount of retrieved sentences by the dictionary. The F1 score is defined as the harmonic mean of recall and precision:

$$
F 1=2 *(\text { Recall } * \text { Precision }) /(\text { Recall }+ \text { Precision })
$$

For an initial comparison, we turned the continuous emotional scores computed by the dictionary to the same binary scale that the human coders produced. Table B.3 shows the results for recall, precision and F1 scores.

As can be seen, for most emotions the ed 8 dictionary attains good F1 scores around or above 0.5. In general, the ed8 dictionary attains very good recall scores which are, except for anger, higher than the precision scores. We interpret this result as that the ed8 dictionary retrieves a lot of the sentences classified as emotional by human coders, meaning its classification is complete (due to the good recall scores), yet, due to lower precision values (especially for disgust and pride) it is necessary to treat these results with wariness. When it comes to anger, however, with a precision score of 0.78 it is reasonable to assume that the retrieved sentences can be trusted to a large extent.

However, it is important to compare the performance of the ed 8 to other, off-the-shelve dictionaries that are often used in text analysis studies. To do so, we compare the ed8 
Table B.3: Precision, recall, and F1 score for the ed8 dictionary.

\begin{tabular}{cccccc}
\hline \hline & Actual & Predicted & Precision & Recall & F1 Score \\
\hline Anger & 4582 & 2768 & 0.78 & 0.47 & 0.59 \\
Fear & 1893 & 2778 & 0.44 & 0.65 & 0.53 \\
Disgust & 889 & 1823 & 0.33 & 0.67 & 0.44 \\
Sadness & 1919 & 2700 & 0.45 & 0.64 & 0.53 \\
Joy & 1427 & 1773 & 0.47 & 0.59 & 0.52 \\
Enthusiasm & 1990 & 2298 & 0.46 & 0.53 & 0.49 \\
Pride & 1563 & 2223 & 0.35 & 0.49 & 0.41 \\
Hope & 2873 & 2822 & 0.56 & 0.55 & 0.55 \\
\hline
\end{tabular}

dictionary to the commonly used LIWC dictionary (Linguistic Inquirer and Word Count, Tausczik and Pennebaker 2010) and the NRC EmoLex dictionary (Mohammad and Turney 2010). These lexica are among the few dictionaries available that not only include general categories for positive and negative tone but also categories for discrete emotions. The LIWC dictionary includes anger, anxiety (treated here as comparable to fear), and sadness. The NRC EmoLex dictionary includes anger, fear, disgust, sadness, joy, anticipation, surprise, and trust. Both dictionaries include a German lexicon versions. While the German version of the NRC EmoLex dictionary has been translated automatically using Google Translate, the German LIWC dictionary has been translated and adapted manually to the German language context (Meier et al. 2019). The precision, recall, and F1 scores for both dictionaries are shown in Table 4 and 5 .

Table B.4: Precision, recall, and F1 score for the NRC EmoLex dictionary.

\begin{tabular}{cccccc}
\hline \hline & Actual & Predicted & Precision & Recall & F1 Score \\
\hline Anger & 4583 & 600 & 0.76 & 0.10 & 0.18 \\
Fear & 1893 & 780 & 0.32 & 0.13 & 0.19 \\
Disgust & 889 & 321 & 0.22 & 0.08 & 0.12 \\
Sadness & 1919 & 999 & 0.31 & 0.16 & 0.21 \\
Joy & 1773 & 694 & 0.32 & 0.15 & 0.21 \\
\hline
\end{tabular}

Table B.5: Precision, recall, and F1 score for the LIWC dictionary.

\begin{tabular}{cccccc}
\hline \hline & Actual & Predicted & Precision & Recall & F1 Score \\
\hline Anger & 4583 & 1612 & 0.73 & 0.26 & 0.38 \\
Fear & 1893 & 809 & 0.40 & 0.17 & 0.24 \\
Sadness & 1919 & 977 & 0.48 & 0.24 & 0.32 \\
\hline
\end{tabular}

The tables show that the novel ed8 dictionary substantially outperforms both the LIWC and NRC EmoLex. The highest F1 score for the NRC dictionary is 0.21 , for the LIWC dictionary 0.38. Similarly, the individual scores for precision and recall for all emotions under scrutiny are lower than the respective scores for the ed8 dictionary (with the exception of the sadness precision score of the LIWC dictionary). The automatically translated German version of the NRC EmoLex dictionary shows the worst 
performance. In general, the recall scores for both dictionaries show substantially low values. These numbers indicate that the two off-the-shelve dictionary find only a fraction of the sentences that humans judge as emotional.

In this initial comparison we forced the continuous scale of the dictionaries into a binary variable. In the following, we check whether higher emotional scores of the dictionaries also correlate with higher emotionality as judged by human coders. Human coders were only faced with a binary decision (whether or not a given emotion was associated with a sentence). Nevertheless, we can construct a categorical variable based on the agreement/disagreement of the human coders. This means that instead of forcing the emotional scores of the dictionary into a binary variable, we turn the human judgment into a categorical variable, based on differences across human coding. This approach perceives differences between coders as real variation, in our case variation in emotional strength (Young and Soroka 2012, see). Thus, human judgment was classified as "very emotional" (e.g. very angry) when four or five coders coded the sentence as associated with the respective emotion (e.g. anger). When two or three coders agreed on one emotion, the human judgment was categorized as "emotional" (e.g. angry) and finally, when none or only one of the coders associated the sentence with the respective emotion the human code was categorized as "not/slightly emotional" (e.g. not/slightly angry). We would expect that the normalized emotional scores significantly increase from the lowest category (not/slightly emotional) to the highest (very emotional).

Figures B.1 and B.2 plot the normalized emotional scores and their 95\% confidence intervals for all positive and negative emotions across three categories of human judgment, grouped by dictionary. These Figures show that the NRC EmoLex dictionary shows either no or only slight increase across the different categories of human judgement. Thus, the NRC cannot reliably distinguish among human judgements. In contrast, the ed 8 and the LIWC dictionary exhibit clearly positive slopes across the scale of human judgment. However, the ed 8 shows the best performance which discriminates the categories from "not/slightly" to "very emotional" in a statistically significant manner with comparably small confidence intervals. The LIWC dictionary shows greater uncertainty and does not discriminate significantly between "angry" and "very angry", as can be seen in the first panel of Figure B.1.

Overall, the novel ed8 dictionary applied in this study outperforms widely used offthe-shelve dictionaries in several measures across all comparable emotions. It shows robust F1 scores and substantially improves the accuracy of automated text classification compared to other dictionaries. 
Figure B.1: Comparing human judgement against normalized emotional scores (negative emotions).
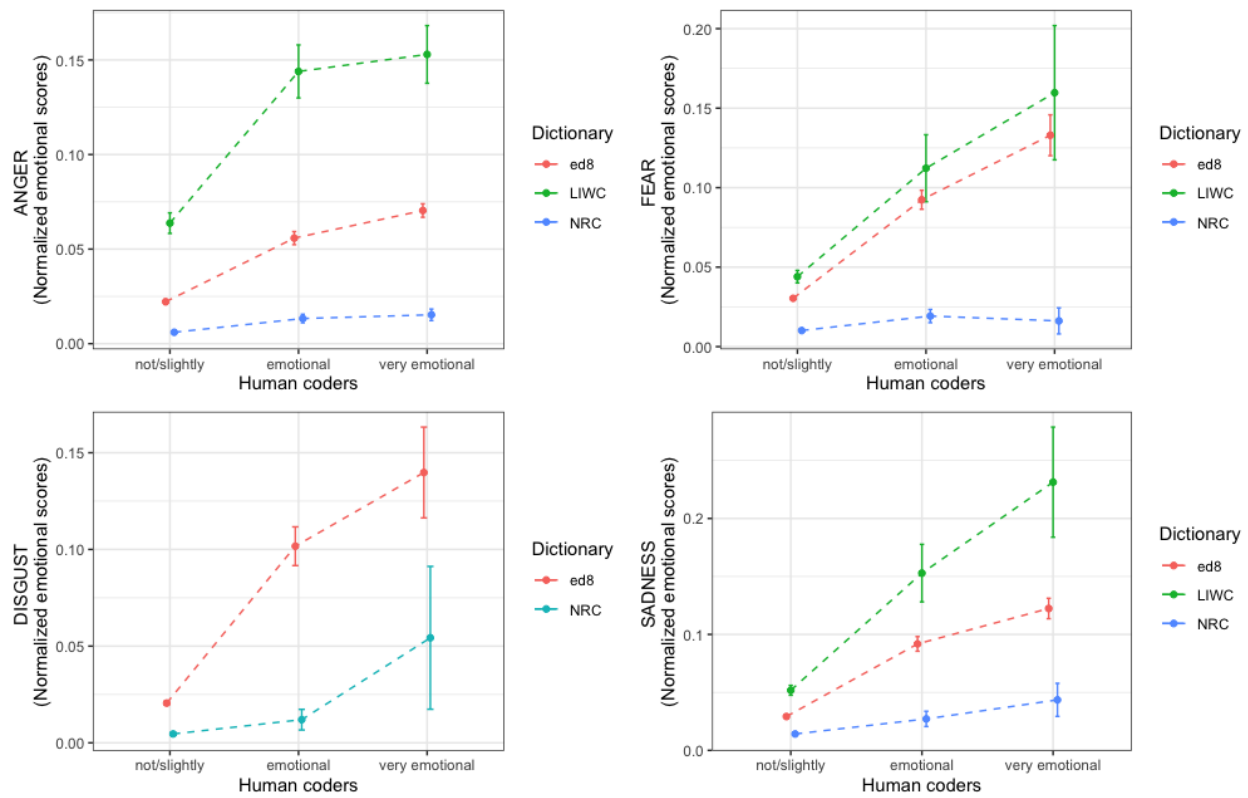

Figure B.2: Comparing human judgement against normalized emotional scores (positive emotions).
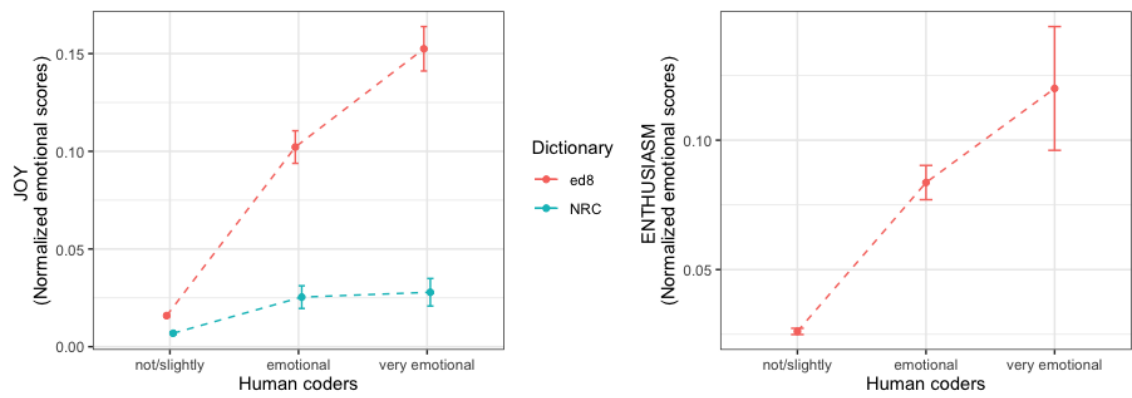

Dictionary

$\rightarrow$ ed8
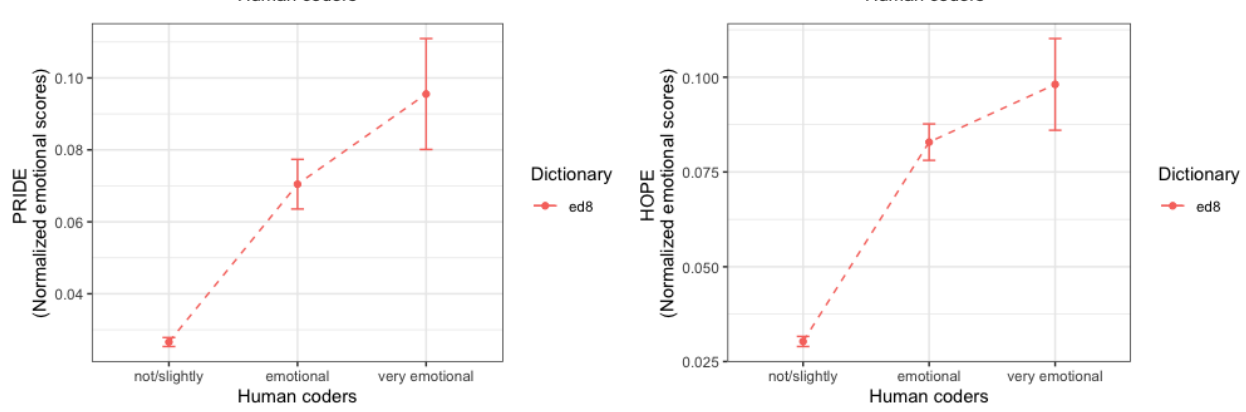


\section{Examples of text scoring high on each emotion}

\section{C.1 Examples of speeches scoring high on anger}

21.11.2018, Andre Poggenburg, AfD, Sachsen-Anhalt. "Dear Mrs von Angern, once again you have deliberately misrepresented the position of AfD. The AfD is concerned with real equality of opportunity rather than the imposition of quotas. That is the only correct approach. Take note that you and your left-wing political brethren are mentally courting a religion that has oppression and discrimination against women on its agenda. Against this background, all your alleged efforts to improve women's opportunities and their equality are nothing but mockery, ridicule and hypocrisy. You should be ashamed of yourself in front of the women in this country."

22.06.2017, Kurt Wansner, CDU, Berlin. "[...] Whoever attacks the police attacks us all. The District Assembly condemns the feigning of an emergency and the targeted attack on police forces in Riga Street. The Assembly also condemns the serious interference with traffic the following night and the subsequent repeated attack on police officers. Violence by left-wingers, autonomists and supporters of the autonomous scene has reached a new level of insidiousness and brutality, which urgently needs to be stopped. The police are there to protect everyone. Whoever attacks the police attacks the whole of society. He attacks us all."

30.06.2017, Thomas Jung, AfD, Brandenburg. "Mr President, Mrs Johlige, it was really a low point from the left to defame us like this. Unlike you, we do not employ and have people who were in the RAF like you on the left. I only remind you of Inge Viett, who is now employed by the Left as a mass murderer. And on the other hand I say to you: These very people, these left-wing extremists, these leftists are attacking people. If you had experienced what has been described to me, where small children here in Potsdam were finally attacked by a lynch mob of you and your fellow-minded people, then you would simply keep quiet!"

\section{C.2 Examples of speeches scoring high on fear}

03.06.2016, Thomas Höse, The Left, Sachsen-Anhalt."Mr President, honourable Members of Parliament. December, Berlin, truck: 55 injured, 12 dead. 1 January, Istanbul, firearm: 67 injured, 39 dead. 5 January, Gothenburg, explosives: one injured. February 3, Paris, machete: two injured. March 18, Paris. Firearm: one wounded, one dead. March 22nd, London, knife. Car: 41 injured, six dead. March 24, Grozny, firearms, explosives: 12 dead. April 3, Saint Petersburg, explosives: 51 wounded, 14 dead. April 7, Stockholm, firearms, truck: 15 injured, five dead. April 20, Paris, firearm, truck: 15 injured, two dead. 19 May, Milan, knife: three injured, two dead. May 22, Manchester, bomb: 59 injured, 23 dead. 3 June, London, knife, van: 48 injured, 11 dead. June 19, London, van 10 injured, 11 dead. Ladies and gentlemen! As a result of these attacks, which only cover the last six months, do the LEFT and the GREENS seriously believe that Europe, unlike Afghanistan, is a safe territory, or do they, in your words, offer a prospect of staying? That is completely absurd and unworldly."

18.11.2015, Bessin, AfD Brandenburg."Mr President, honourable Members of Parliament. Dear guests! Violence prevails in our society, and not just since Friday . 
There is violence in the family, violence in schools, violence is portrayed in the media, violence exists in social discourse and also in political debate. We have already heard a lot about violence and terror today. The cruelty of the terrorist attacks in Paris is hard to put into words. The motion that I have tabled, which is now to be discussed, aims to raise awareness of the facts about the increase in violence against political activists and to discuss this with all of you. However, as I can see from the agenda, the clan of SPD, CDU, Left and Greens has agreed not to discuss it with us. [...] But where does that come from, where does this potential for violence come from? It is not us who are rushing . I am surprised, Mr Woidke, that you are making yourself heard here. It is not us who are polemicising against refugees and demonstrating against them - perhaps you should listen to us - but it is us who are protesting against the wrong refugee policy, which we believe the Chancellor and our state government are pursuing. And we have the right to express this opinion. Yes, we say out loud that we do not think this way of influx of foreign people is right, we clearly reject it.[...]"

\section{C.3 Examples of speeches scoring high on disgust}

12.10.2017, Heiner Garg, FDP, Schleswig-Holstein."Mr President, ladies and gentlemen. Ladies and gentlemen I find what you have just presented here disgusting. I find it really disgusting that you are making a mockery of the past we look back on, making a mockery of victims of that past. You can stand by that motion however you want. The debate on the substance, the debate on the substance has been conducted. I do not want to interfere in that. What you have just organised here is quite simply unworthy of this Parliament. It is not proper for a parliament to make fun of history in the way you have just made fun of it from the lectern."

19.12.2018, Ulrich Siegmund, AfD, Sachsen-Anhalt."Mr Grube, thank you for giving me the opportunity to deal with another topic in this context. At the beginning of your speech, you celebrated the Jusos adequately for their work. I would like to ask you what the SPD Group in Saxony-Anhalt, and also yourself, think about the current demand by the Young Socialists for late abortion to be legalised, that is to say, for a living baby to be killed by an injection of potassium into the heart and the body then to be taken out through the womb in an artificially induced birth lasting approximately 10 to 20 hours, so that this mother gives birth to a stillborn child. How do you feel about this disgusting and emotionally cold demand? That would interest me. Thank you."

\section{C.4 Examples of speeches scoring high on sadness}

21.01.2015, Ralf Stegner, SPD, Schleswig-Holstein."Mr President, ladies and gentlemen, it is a sad occasion on which we began today's plenary session with a minute's silence for the victims of terrorist violence in recent weeks. I am glad that we will continue it with a clear commitment by the Schleswig-Holstein Landtag to a peaceful, cosmopolitan and diverse society. Together we mourn all the victims of violence. Our special sympathy these days goes to the victims and relatives of the cruel attacks against the editors of the French satirical magazine Charlie Hebdo, the supermarket for kosher food in Paris and the murdered policeman. Once again, these were acts of terrorist violence that cannot be justified by anything. Violence is never right or acceptable, no matter 
what the aim, ideology, religion or worldview of the perpetrators."

21.01.2015, Daniel Günther, CDU, Schleswig-Holstein."Mr President, ladies and gentlemen. Stunned, horrified and saddened by the barbaric murders of Paris. The brutality and cold-bloodedness of the murderers - this is what we see when we look at the pictures - shakes us again and again. 17 innocent people have lost their lives because terrorists have put their murderous and hateful plan into action, 17 people whose families and friends have to live on without them. They have our deepest sympathy. We mourn with our French neighbours. These heinous murders were a targeted attack on the very foundations of Europe: on freedom of expression and of the press, on our entire free democratic order and on our common values. In the midst of their grief, our French neighbours have sent an important and courageous signal: they will not bow to terrorists; they will not let themselves be brought to their knees by terrorist Islamists. The impressive demonstrations involving millions of people have sent out a common signal which has had an incredibly positive effect throughout Europe. That is why I think it is also a very good sign that we in the Schleswig-Holstein Landtag have today agreed on a joint motion on this issue. After all, it must be in our common interest and a common signal from all of us to counter these terrorists. I am very pleased about this signal. My sincere respect goes to the surviving journalists of "Charlie Hebdo". They have not allowed themselves to be intimidated by the terrorists and the barbaric attack on their editorial office."

23.02.2018, Anne Spiegel, Grüne, Rhineland-Palatinate."Mr President, ladies and gentlemen. Without need, no one decides to leave their home and family. Without need no one comes. But those in need shall be allowed to come. Many people are in such dire straits at home that they take the life-threatening flight across the Mediterranean. They seek protection in Europe. In the last few days alone, hundreds if not thousands have drowned in front of Fortress Europe. I am stunned when I see the pictures of this disaster and it makes me incredibly angry."

\section{C.5 Examples of speeches scoring high on joy}

29.03.2019, Bernd Heinemann, SPD, Schleswig-Holstein."Dear Sirs! Ladies and Gentlemen! A small addition from me: 62 years of the Treaty of Rome is a history of prosperity, equality, sustainability, peace, democracy, solidarity and freedom, not of envy, selfishness and isolation. Dear Alternative for Germany, we have a European Parliament. Yes, we have one, and we should have a bigger one. We also want more democracy in Europe. And yes, we have an anthem based on Friedrich Schiller's poem "An die Freude", set to music by Ludwig van Beethoven with the 9th Symphony. This anthem is indeed an expression of joy, and we have reason to rejoice."

28.02.2018, Jürgen Keck, FDP, BaWu."Mr President, ladies and gentlemen. It is already 15 years since the European Year of People with Disabilities was held - in 2003. The motto - as Minister Lucha suggested earlier - was: "Not about us without us". This still applies to us 15 years later. Thank you very much, Mrs Aeffner, for your active cooperation. I hope that you will be able to continue to contribute actively. In Baden-Württemberg, this was associated with the initiative "In the middle instead of on the outside". Even today, discussions, events and projects of the handicapped aid are still very much under this motto. It is a particular pleasure for me that we are today 
discussing the implementing law for the Federal Participation Act at its first reading. I would like to comment on this with: "What lasts long will finally be good." "

15.05.2019, Jörg Denninghoff, SPD, Rhineland-Palatinate. "Mr President, ladies and gentlemen, Mrs Schleicher-Rothmund. In the last two years, I have already had the opportunity to speak in plenary on the occasion of the Ombudsman's annual report, and this year is another great pleasure for me. I am even particularly pleased that now, after more than four decades, for the first time a woman is the Ombudsman of the Land of Rhineland-Palatinate."

\section{C.6 Examples of speeches scoring high on enthusiasm}

15.01.2015, Benedikt Lux, Grüne, Berlin. "Madam President, ladies and gentlemen. Dear Mr Herrmann! We naturally welcome your proposal to strengthen voluntary work with the voluntary fire brigade in Berlin. As you have said, the 1400 or so volunteers are doing indispensable work for the city. They are also the backbone of the professional fire brigade with 3,600 people, and it would be impossible to imagine major events such as New Year's Eve without them. They ensure that dangers for Berliners are averted and help is provided in the event of fires, disasters, floods, etc. Therefore also from our side, from Bündnis 90/Die Grünen: Many thanks to the helpers!"

24.05.2018, Wolfgang Aldag, Grüne, Sachsen-Anhalt. "[...]137 schools in SaxonyAnhalt received the award "School without racism School with courage". These schools are specifically committed to civil courage and a positive school climate. We, the Green parliamentary group in Saxony-Anhalt, think this is important and right; and we are not alone. Many representatives from this House support us. Many personalities from the fields of sport and music as well as representatives of the economy of this state stand as sponsors with their name and their conviction behind the project "School without racism School with courage". A large majority here in this House and a large majority in society support the work of the Courage Schools and stand firmly by their side. We will continue to do so[...]."

\section{C.7 Examples of speeches scoring high on pride}

7.03.2019, Harm Rykena, AfD, Niedersachsen. "Thank you very much. Madam President, ladies and gentlemen. With regard to this motion, it should be noted that all the political groups in the Lower Saxony State Parliament are in agreement and wish to give all possible support to the universities in Lower Saxony which are in the application procedure for the status of an Excellence University. We are all proud of the excellent work that has been and will be done at these universities during the application process. There is therefore no need for debate. That is why I do not want to go any further at this point and take up the time of the Landtag. Perhaps colleagues from the other groups will feel the same way. The AfD will be happy to agree to the motion. Thank you very much."

11.12.2018, Bernhard Braun, Grüne, Rhineland-Palatinate. "Mr President, ladies and gentlemen. I want to start by saying this because it has not yet been said today and I believe it must be said: The situation in Rhineland-Palatinate is good. The situation in Rhineland-Palatinate is actually very good. I believe that the situation 
in Rhineland-Palatinate for the people of Rhineland-Palatinate has never been better. I believe that this is why we, as the government, as the groups that support the government, but also, of course, as the opposition, who make proposals in this budget, can be proud of this state of Rhineland-Palatinate. The people here are doing well, they are safe, they are well equipped, they have good education at their disposal, and they can be satisfied with it[...]"

23.03.2017, Heiko Sippel, SPD, Rhineland-Palatinate. "Madam President, ladies and gentlemen. A well-functioning constitutional state is the guarantor of democracy and freedom, of a high level of security, of the citizens' right to justice and of reliable framework conditions for society and the economy. Day after day, the judiciary in our country does an excellent job of meeting these high standards. For this, all judicial staff in the very different areas of responsibility deserve our thanks and recognition. Especially in times like these, when the rule of law and the validity of the law in many countries of the world are in question, we can be proud of the merits of our liberal democratic legal system[...]"

\section{C.8 Examples of speeches scoring high on hope}

13.10.2016, Wolfgang Reinhart, CDU, BaWu. "[...] All these changes - these are the issues of the future that must move us - are about our image of humanity. Do we see change only as an imposition from which we must protect employees, or do we trust in the freedom, talents, motivation, development and responsibility of the individual? Let us give this freedom room. Finally, the working world of the future will make possible what generations have dreamed of: a freer, more self-determined, more interesting and inspiring life. Let us seize this opportunity. Let us say yes to this future. Let us make Baden-Württemberg a model location for this new work, ladies and gentlemen."

29.01.2015, Ralf Seekatz, CDU, Rhineland-Palatinate. "Madam President, ladies and gentlemen. This year's theme is development policy under the motto "Our world, our dignity, our future". The aim of this EU Development Year 2015 is to inform and involve citizens about cooperation in the field of EU development aid via the individual Member States and - I think this is particularly important - to raise awareness of the benefits of development aid. With good development cooperation, a great deal can be achieved in terms of shaping globalisation fairly, preserving the environment, but above all peace, freedom and democracy and human rights. The future of the people in developing countries, and thus also our own future, depends decisively on a good development policy. Promoting democracy and peace can only succeed if we have courage, hunger and disease in these countries under control."

23.05.2018, Heike Scharfenberger, SPD RLP. "Mr President, ladies and gentlemen. Mr President, ladies and gentlemen, the European Union is essentially an idea of human coexistence, of peace and freedom, of responsibility and social justice, of equal opportunities and humanity, of economic cooperation and joint progress. It is a historically unique [...]." 


\section{Additional analyses}

Table D.1 shows how the emotions we use as dependent variables are correlated in our dataset.

Table D.1: Correlations between the level of each emotion.

\begin{tabular}{ccccccccc}
\hline \hline & Anger & Fear & Disgust & Sadness & Joy & Enthusiasm & Pride & Hope \\
Anger & 1.0000 & & & & & & & \\
Fear & 0.6413 & 1.0000 & & & & & & \\
Disgust & 0.5107 & 0.4950 & 1.0000 & & & & & \\
Sadness & 0.5797 & 0.6930 & 0.4701 & 1.0000 & & & & \\
Joy & -0.0740 & -0.0766 & -0.0497 & -0.0626 & 1.0000 & & & \\
Enthusiasm & -0.0376 & 0.0065 & -0.0163 & -0.0086 & 0.1193 & 1.0000 & & \\
Pride & -0.0656 & -0.0542 & -0.0378 & -0.0457 & 0.5107 & 0.3109 & 1.0000 & \\
Hope & -0.0403 & 0.0093 & -0.0007 & 0.0017 & 0.1462 & 0.5564 & 0.3111 & 1.0000 \\
\hline
\end{tabular}

Figure D.1 shows the distribution of our eight outcome variables.

Figure D.1: Distribution of the eight outcome variables used in the main analyses.
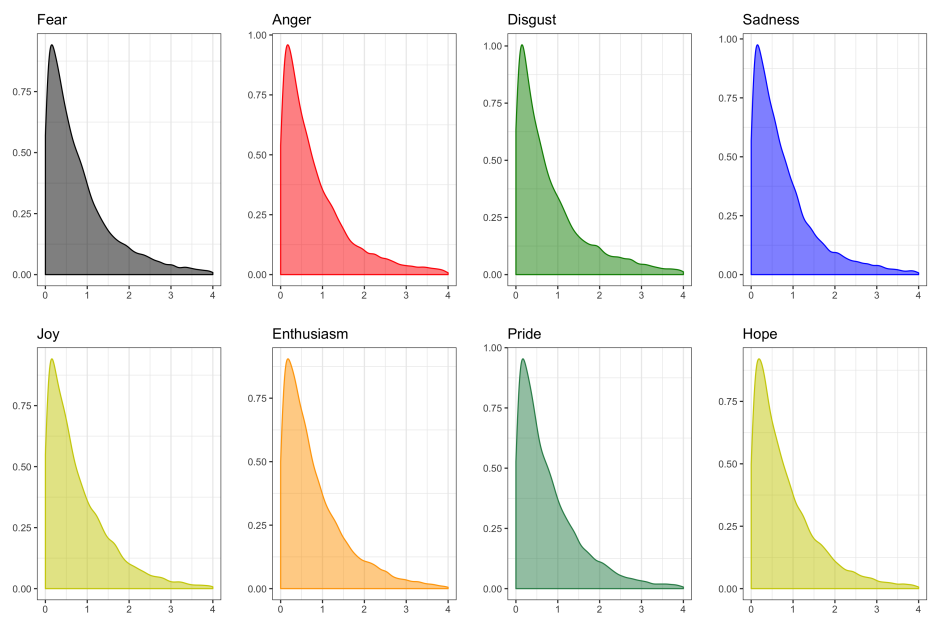

We also replicate the analyses depending on the government status of the MP's party. Concretely, we replicate the analyses for MPs whose party had been in government in the legislature leading up to the state election when AfD MPs first entered parliament; for MPs whose party was in government in the legislature that followed that election; and for MPs whose party was in government in both legislatures. The results, shown in Figure D.2 show little heterogeneity across these categories. We then repeat this exercise for MPs of opposition parties. As with before, we replicate the analyses for MPs whose party had been in opposition in the legislature leading up to the state election when AfD MPs first entered parliament; for MPs whose party was in opposition in the legislature that followed that election; and for MPs whose party was in opposition in both legislatures. Again, as shown in Figure D.3, we find little evidence heterogeneity across the three categories. In all these six subsamples, the effects are very similar to the main ones shown in Figure 2.

Because the analyses include actors from two legislatures, a potential concern is that not all MPs are re-elected. To make sure changes in the MPs that compose each state legislature are not driving the results, we replicate the analyses shown in Figure 2 using only MPs that were elected in both legislatures: before and after radical right politicians 
Figure D.2: Heterogeneous treatment effects on the government status of the MP's party.

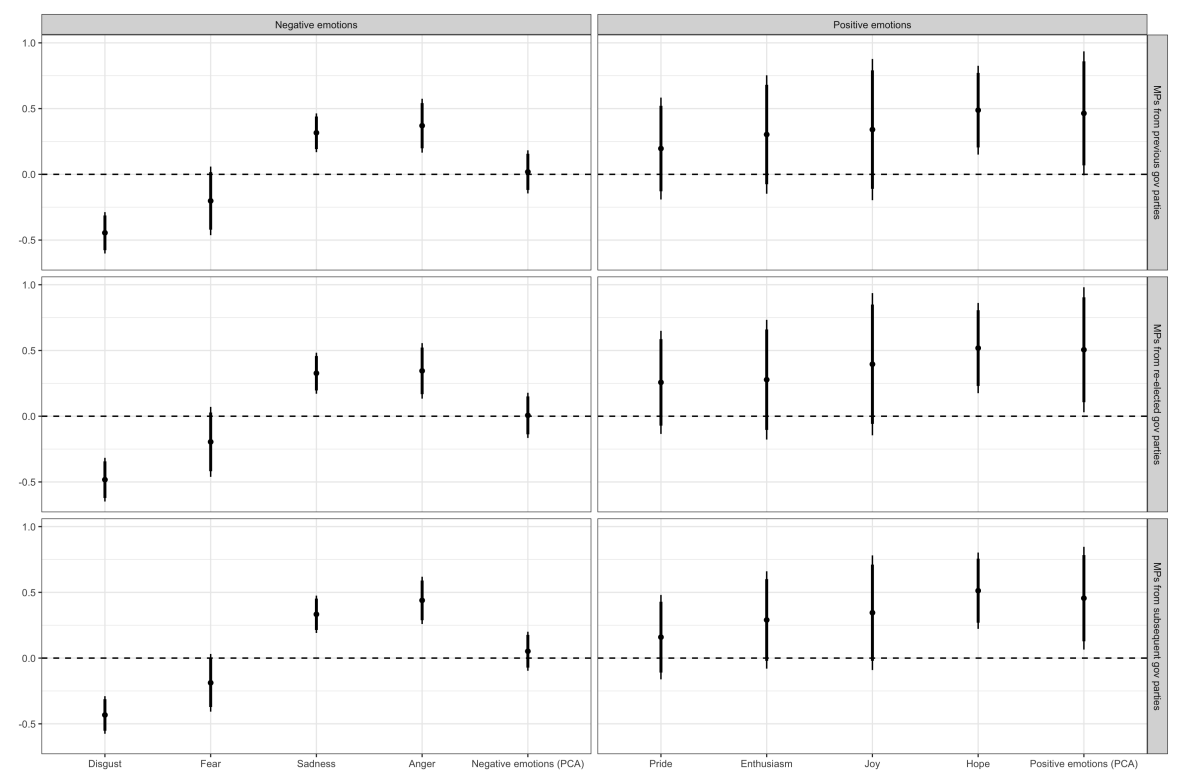

Notes: Dotted lines represent 95\% Confidence Intervals. All dependent variables are standardized. The models include actor-level and months-since-election fixed effects. Standard errors are clustered by actor.

Figure D.3: Heterogeneous treatment effects on the opposition status of the MP's party.

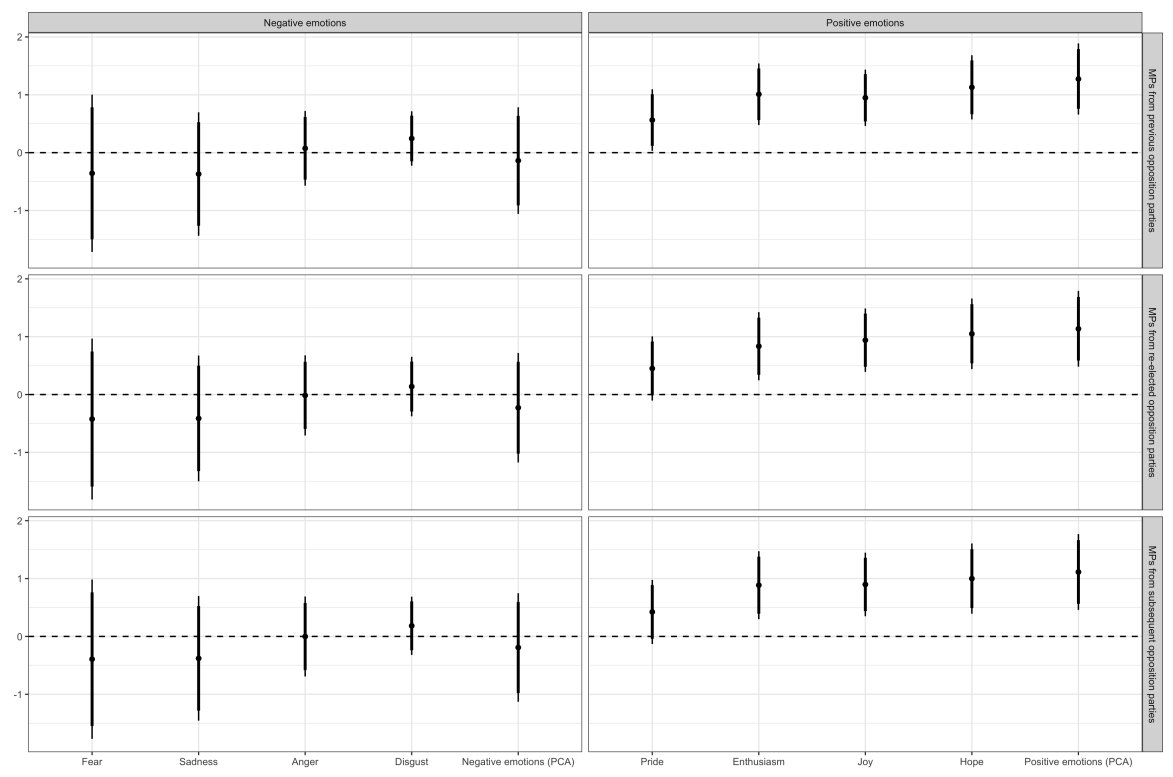

Notes: Dotted lines represent 95\% Confidence Intervals. All dependent variables are standardized. The models include actor-level and months-since-election fixed effects. Standard errors are clustered by actor. 
Figure D.4: Replication of the main analyses shown in Figure 2 using only MPs that were re-elected.

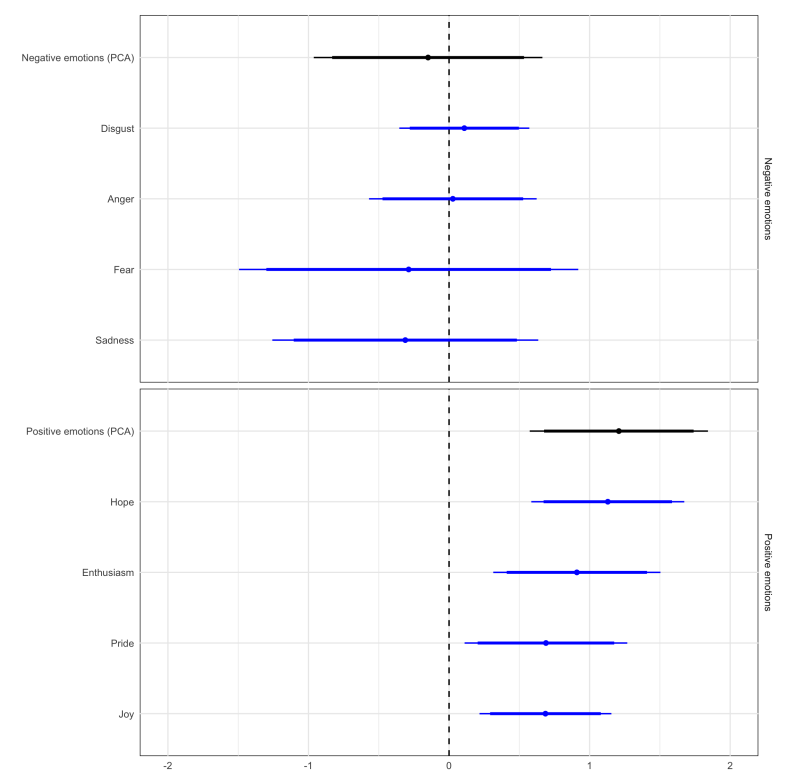

Notes: Thick lines represent 95\% Confidence Intervals; thin lines represent 90\% Confidence Intervals. All dependent variables are standardized. The models include actor-level and months-since-election fixed effects. Standard errors are clustered by actor.

entered parliament. These results, shown in Figure D.4, are very similar to the main analyses.

In the main analyses shown in Figure 2, we remove speeches of length below 100 words. To make sure this decision is not driving the results, in Figure D.5 we replicate the analyses without removing these speeches. The pattern remains similar to the one in Figure 2. The only difference is that the magnitude of the effects becomes smaller, as one should expect given that we include more data with no substantive interest, which should dillute the size of the overall effects.

In the main analyses, the data are grouped by month-since-election. To make sure this aggregation is not driving the results, we replicate the analyses on a dataset that is aggregated by calendar date, instead of by month-since-election as in the main analyses shown in Figure 2. As with the main analyses, we include politician and month-sinceelection fixed effects. As Figure D.6 shows, the results remain very similar.

The main analyses in Figure 2 include politician and month-since-election fixed effects. While these control for differences in the level of emotionality as one moves closer or farther away from the date of the election, they do not control for time trends that are unrelated to the timing of the election. To make sure longitudinal trends in the level of emotionality used by MPs are not driving the results, in Figure D.7 we replicate the main analyses adding calendar-year fixed effects. The results remain very similar.

We also replicate the analyses shown in Figure 2 with state fixed effects instead of politician fixed effects. As shown in Figure D.8, the results remain very similar.

As shown in Figure D.1, the distribution of the outcome variables is rather skewed. For this reason, we also replicate the analyses shown in Figure 2 with logged outcomes. 
Figure D.5: Replication of the main analyses shown in Figure 2 without excluding speeches with less than 100 words.

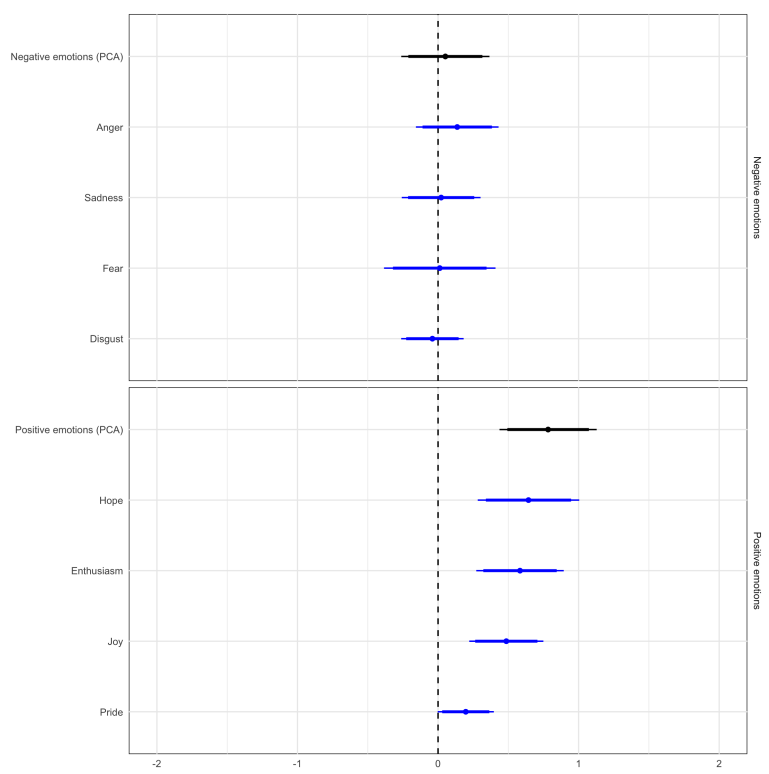

Notes: Thick lines represent 95\% Confidence Intervals; thin lines represent $90 \%$ Confidence Intervals. All dependent variables are standardized. The models include actor-level and months-since-election fixed effects. Standard errors are clustered by actor.

Figure D.6: Replication of the main analyses shown in Figure 2 without aggregating the data monthly.

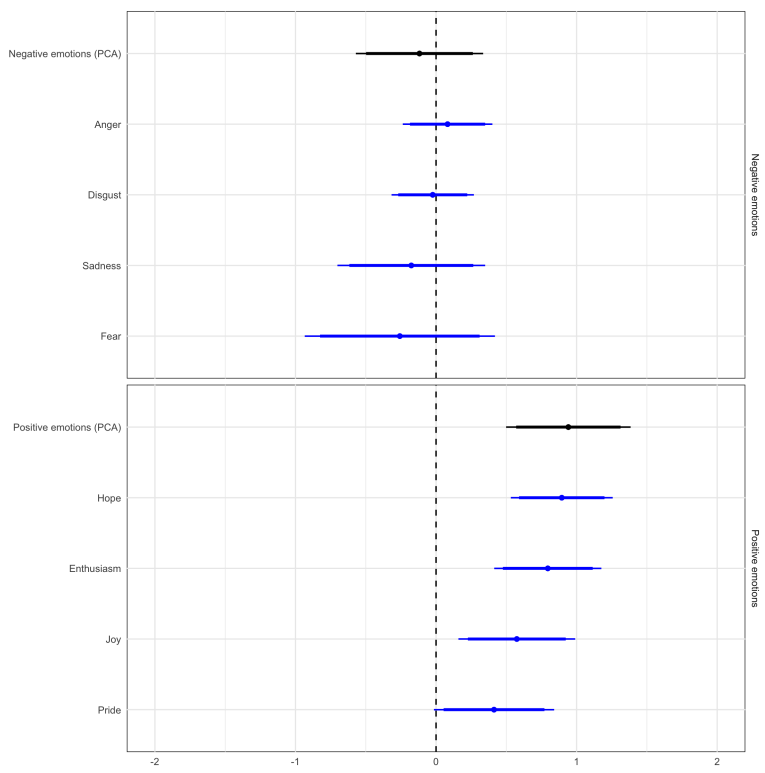

Notes: Thick lines represent 95\% Confidence Intervals; thin lines represent 90\% Confidence Intervals. All dependent variables are standardized. The models include actor-level and months-since-election fixed effects. Standard errors are clustered by actor. 
Figure D.7: Replication of the main analyses shown in Figure 2 adding calendar-year fixed effects.

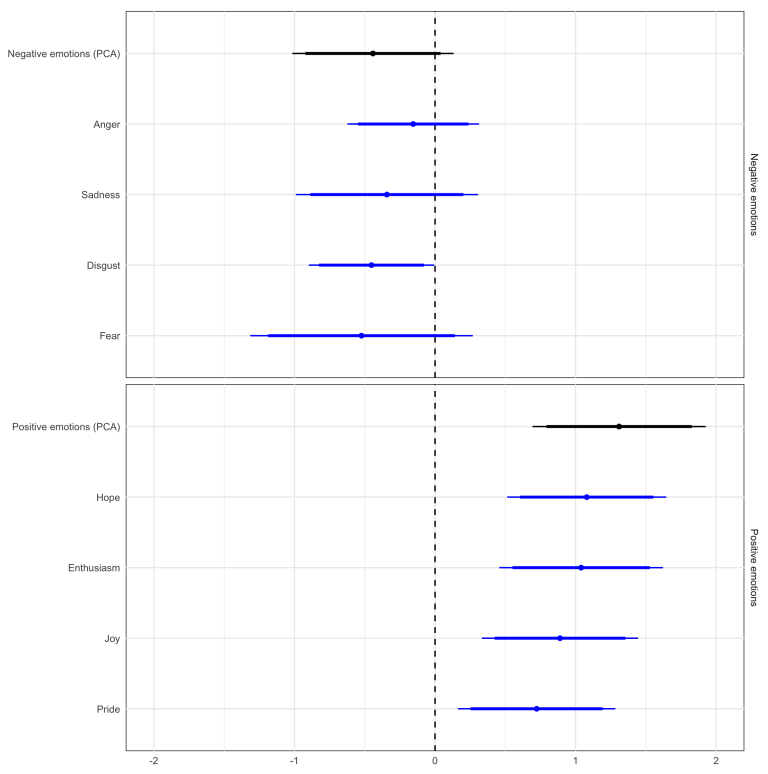

Notes: Thick lines represent 95\% Confidence Intervals; thin lines represent $90 \%$ Confidence Intervals. All dependent variables are standardized. The models include actor-level and months-since-election fixed effects. Standard errors are clustered by actor.

Figure D.8: Replication of the main analyses shown in Figure 2 with state fixed effects instead of politician fixed effects.

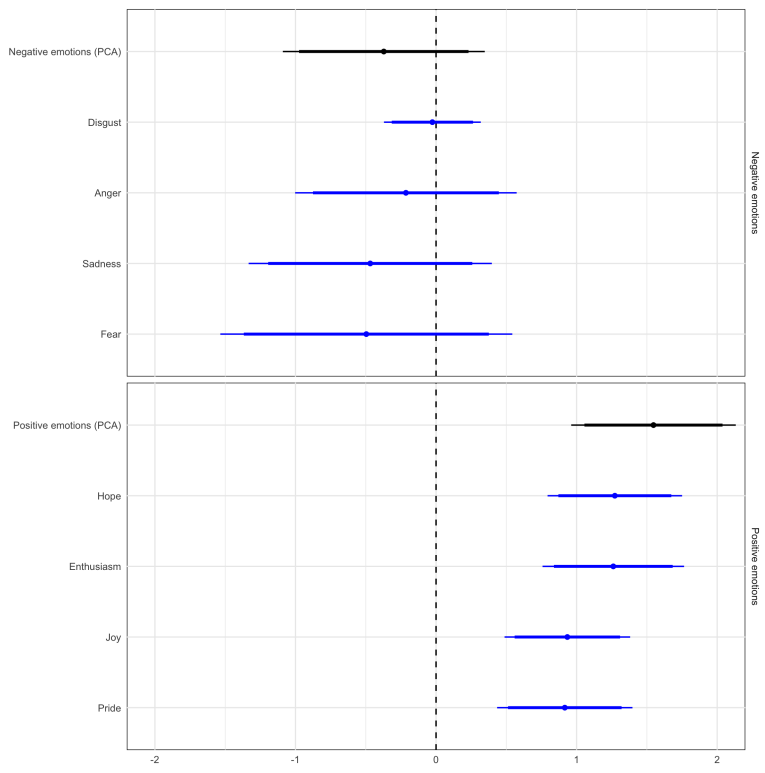

Notes: Thick lines represent 95\% Confidence Intervals; thin lines represent 90\% Confidence Intervals. All dependent variables are standardized. The models include actor-level and months-since-election fixed effects. Standard errors are clustered by actor. 
Figure D.9: Replication of the main analyses shown in Figure 2 with logged dependent variables.

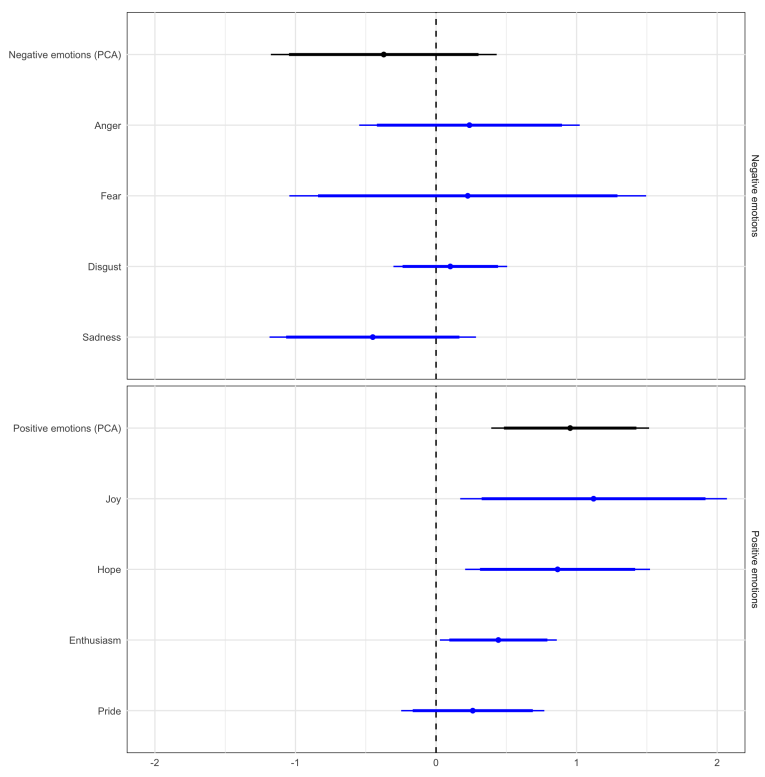

Notes: Thick lines represent 95\% Confidence Intervals; thin lines represent 90\% Confidence Intervals. All dependent variables are standardized. The models include actor-level and months-since-election fixed effects. Standard errors are clustered by actor.

Because many of our observations have a value of 0 in some outcome variable, we use the $\log$ of the value of each variable plus 1, so that no zero remains. As shown in Figure D.9, the results remain very similar to the main ones, even if the effect on pride is no longer significant at traditional thresholds.

Figure D.10 presents a robustness check where we replicate the analyses after sequentially removing one all observations from each state.

As discussed in the text, the analyses shown in Figure 3 include the Greens as a mainstream party. To make sure this choice is not driving the results, we replicate the Figure excluding the Greens. This replication is shown in Figure D.11. These results are very similar to the ones shown in Figure 3.

The analyses that compare the effects depending on the ideology of the MP's party, as shown in Figure 4 do not include the left-populist party The Left. To make sure this choice is not driving the results, Figure D.12 replicates these analyses without removing these MPs. The effects remain stronger for left-wing MPs than for right-wing ones. The difference, however, is slightly smaller than the one shown in Figure 4 -as one would expect given that there is no effect on MPs of the left-populist party The Left.

To identify the main topic of each speech, we rely on topic models - specifically structural topic models (STM) (Roberts, Stewart, and Tingley 2014). Before running the topic model, it is necessary to pre-process the text corpus. We used the inbuilt textProcesser function of the stm R package (Roberts, Stewart, and Tingley 2014). The pre-processing steps included the removal of German stopwords, numbers, and punctuation. All words have been reduced to their root form (stemming) and transformed into lowercase letters. Using the prepDocuments function, we also removed very rare terms that appear in less 


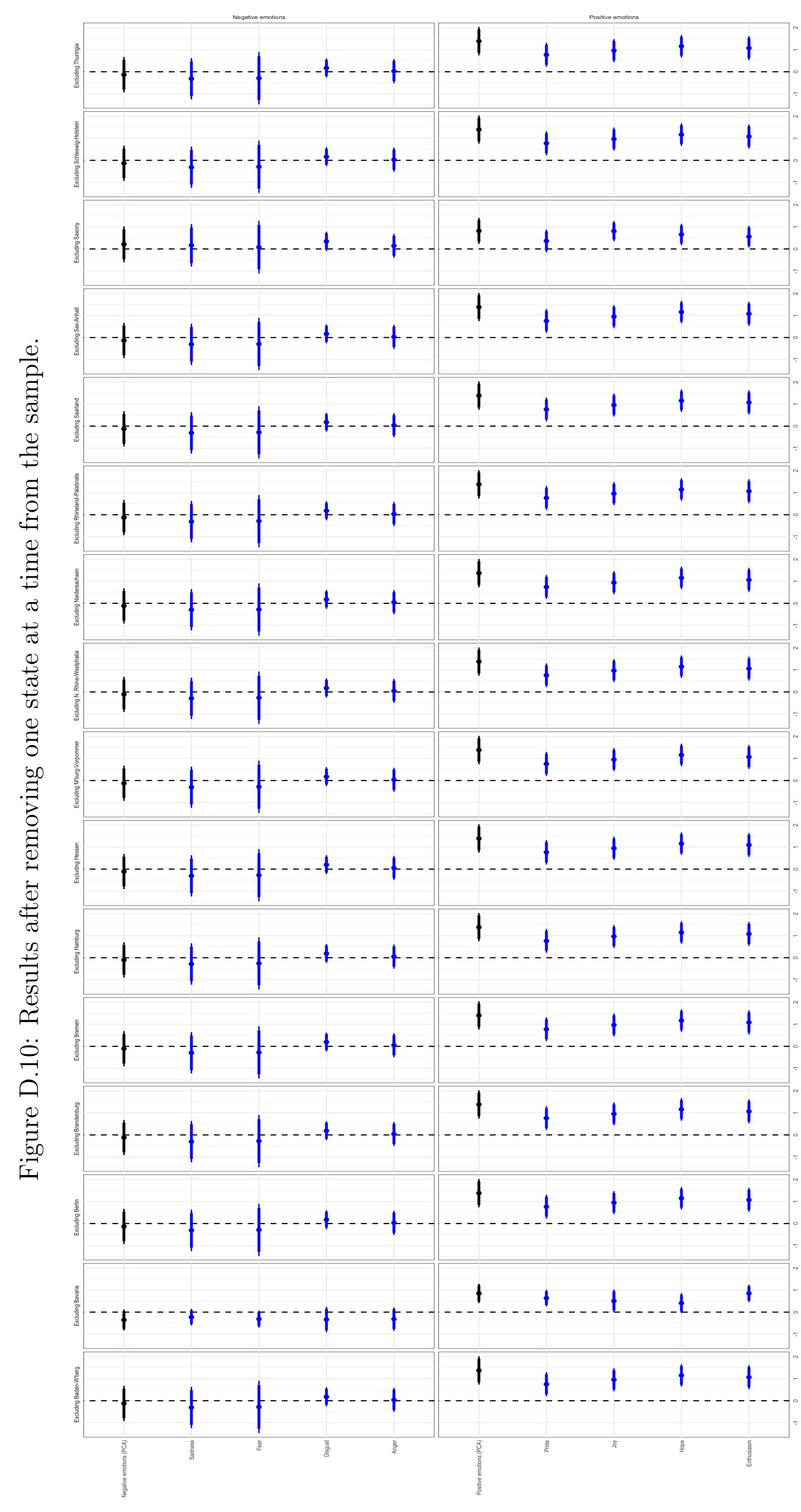

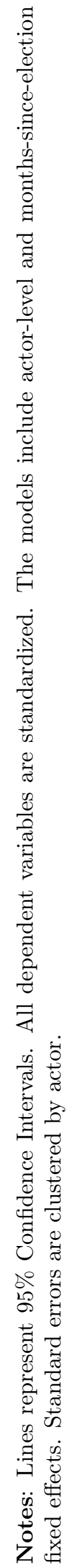


Figure D.11: Who is more affected? Effect on radical left party Die Linke and remaining parties (excluding Greens).

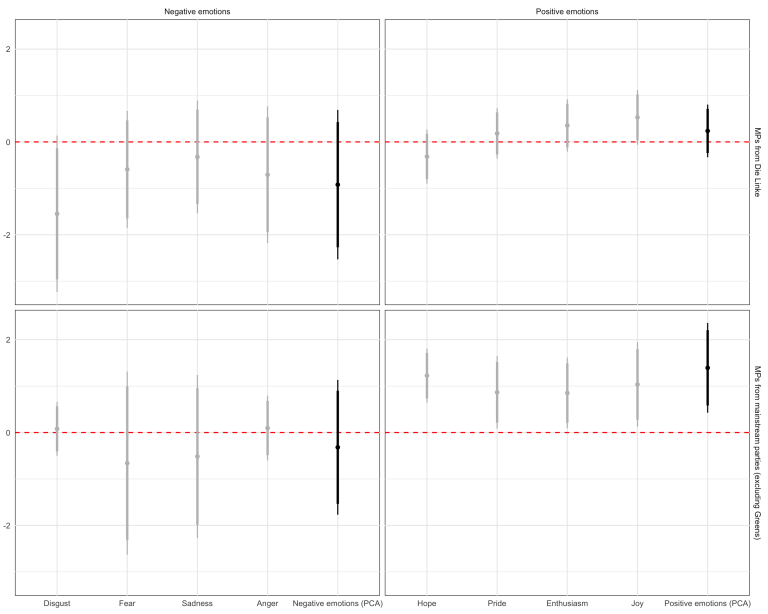

Notes: Thick lines represent 95\% Confidence Intervals; thin lines represent $90 \%$ Confidence Intervals. All dependent variables are standardized. The models include actor-level and months-since-election fixed effects. Standard errors are clustered by actor.

Figure D.12: Effect conditional on the ideology of the MPs (without excluding MPs from The Left).

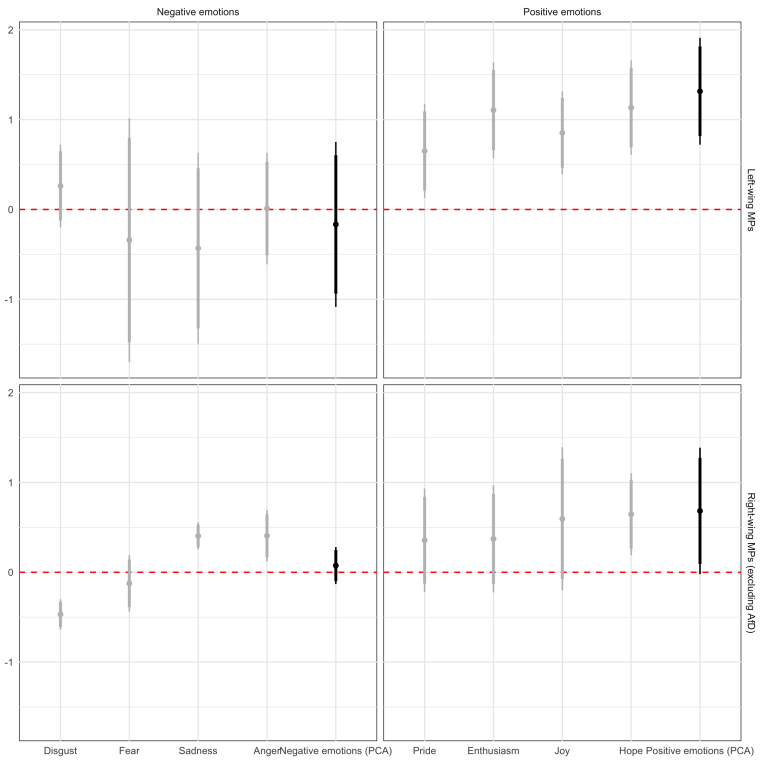

Notes: Thick lines represent 95\% Confidence Intervals; thin lines represent $90 \%$ Confidence Intervals. All dependent variables are standardized. The models include actor-level and months-since-election fixed effects. Standard errors are clustered by actor. 
Table D.2: Details on the topic model.

\begin{tabular}{crc}
\hline \hline Topic & FREX terms & Labels \\
\hline 1 & beamtinnen, beamten, feuerwehr, polizei, polizistinnen & Police + Security \\
2 & eeg, hektar, windkraftanlagen, windenergi, energien, erneuerbar & Alternative Energy + Agriculture + Environment \\
3 & hochschulen, studierende, hochschul, universität, forschung & Research + University \\
4 & untersuchungsausschus, gutachten, akten, staatsanwaltschaft, behörd & Parliamentary Investigation \\
5 & niedersächsich, wolf, grün, tier, tierschutz, lie + Animal Protection \\
6 & lkw, bahn, pkw, hafen, maut, diesel & Transportation \\
7 & flüchtling, asylbewerb, flüchtlingen, abschiebung, afghanistan & Refugees + Asylum \\
8 & schülerinnen, gymnasium, unterricht, schüler, schuljahr, gymnasium & School + Education \\
9 & gesetzentwurf, änderung, beschlussempfehlung, anhörung, änderungsantrag & Legislation + Law \\
10 & glaub, find, kolleg, ding, diskutieren, ehrlich, versteh & Random words (topic removed) \\
11 & brexit, russland, großritannien, europa, union, europäisch & European Union \\
12 & schulden, ausgaben, schuldenbremse, milliarden, haushalt & Budget \\
13 & staatsregierung, sport, engag, barrierefreiheit, behinderung & Volunteering + Sports + Integration \\
14 & frauen, männer, ehe, geschlecht, mädchen, gleichstellung & Gender equality \\
15 & mindestlohn, arbeitnehm, wohnungsbau, wohnraum, mieten, wohnungen & Labour market + Housing \\
16 & rundfunk, zdf, magdeburg, mdr, rundfunkänderungsstaatsvertrag + Media \\
17 & digitalisierung, ländlich, digital, wlan, industrie & Public Broadcaster + Mural Areas + Economy \\
18 & kinderarmut, erzieherinnen, kita, jugendhilfe, erzieh & Family + Children \\
19 & datenschutz, videoüberwachung, vorratsdatenspeicherung, vollzug, überwachung & Data Privacy + Crime \\
20 & patienten, pfegekamm, pflegekräft, ärzte, kliniken & Health \\
21 & extremismus, antisemitismus, rassismus, islam, rechstsextremismus, linksextremismus & Extremism, Racism, Islam \\
22 & anfrag, beantwortet, anfragen, drucksach, staatssekretär & Procedural \\
23 & bundesrat, länder, bundestag, ländern, kompromiss, bund & Federalism \\
\hline
\end{tabular}

than 50 speeches.

Another key parameter that needs to be determined before estimating the model is $k$, which represents the number of topics. There are no clear rules and no "right" answer to the question of how many topics researchers should choose (Grimmer and Stewart 2013). We decided to run our topic model with 23 topics, based on the STM's searchK function results (Roberts, Stewart, and Tingley 2014) and on the manual examination of the different topics. Having less than 23 topics resulted in the blending of substantially different issues into one combined cluster. On the other hand, having more than 23 topics did not result in more fine-grained topics that deal with substantially different issues. Among the 23 topics identified, one topic has been discarded because it consisted mainly of clusters of random word that are used in most speeches irrespective of the issue they draw upon.

Table D.2 provides some details on this model. It reports the 23 topics, the highest probability terms in each, and the overarching topic it refers to.

\section{E Further speeches that illustrate the arguments made in the section on the mechanism.}

This appendix provides a few additional examples that support the claims made in the section providing qualitative evidence on the mechanism.

In the first place, we provide two additional examples of speeches calling out the radical-right rhetoric radical-right rhetoric as norm breaching and unnacceptable. The first is the speech by Bernhard Lasotta, MP for the CDU (Christian Democrats) in the state of Baden-Württemberg, in May 9th 2018 by : "This is something new that we are experiencing here in the Landtag, that debates are being conducted with words and in fearful and aggressive tones, which in no way contribute to solving problems." Another example comes from a speech by Andreas Glück, MP for the FDP in Baden-Württemberg in November 23 2016: "If you pop things out like the moratorium issue, that's just pure 
populism. Either you don't know better, or-worse - you know better and just care about votes. I just say: "ugh" to your political style."

We then provide further examples of speeches where MPs build a contrast between themselves or their party and the radical right, acting as enforcers of the norms breached by the radical right. The first is the speech by Bjorn Fecker, Green MP in the state of Bremen, in January 25 2017. "I have listened to this [the AfD MP's] speech from beginning to end and I can say that I actually went from one fainting spell to the next. I would like to give an example to show why we need to clearly distinguish ourselves from this speech. Mr Höcke [from AfD] referred to the handling of the memorial in Berlin, deliberately ambiguously spoke of a "memorial of shame" and in this context he made his demand for a "turnaround in memory policy". He directed his attack against Richard von Weizsäcker's speech. According to Höcke, he had given a speech against his own people when he spoke of "liberation day" in 1985. Statements such as those made by $\mathrm{Mr}$ Höcke and the ideology behind them are absolutely unacceptable in our country, and we will stand up against them together; they have no place here. "The second is the speech by Julia Willie Hamburg, MP for the Greens in Niedersachsen, in October 1 2019: "Mr. Wichmann, [your speech] is dishonest, dubious. That's not how we work in this house! Similar to the denunciation platform for teachers, you are only concerned with one thing here: intimidation of legal guardians or intimidation of the people who work every day to make our children self-confident and smart, educated and educated democratic people. We will not let you get away with that, dear colleagues."

Finally, we provide additional examples of MPs using positive emotions to create this contrast. The first example is found in the speech by Cornelia Lüddemann, MP for the Green party in Sachsen-Anhalt, in September 27 2018. She starts her speech with using negative emotions such as sadness and anger to refer to the radical-right rhetoric: "I am sad and saddened, but also angry, by the instrumentalisation of this young person's death by right-wing, nationalist and ethnic movements." Then, the emotional tone of her speech changes as she refers to examples of how the people in her state - and her own party - stand by norms of tolerance and openness, against the radical-right discourse: "The vast majority of people in this state are tolerant and open. [...] It is people like the pensioner who looks after the children when their Afghan mother goes to German lessons. It is the housewife who organizes an international cooking course in the multigeneration house. It is the neighbour who takes the Syrian refugee to football training. It is the students who mega creatively work for the label "School without racism". It is all the people who paint doves of peace on the Köthen market place in order to occupy it democratically. It is the owner of the cleaning company who stands up for his Indian employees. It is the men who, regardless of their own faith, put on a kippah to show We practice solidarity. It is the university professors who want to protect their cosmopolitan small town from Nazi concerts. That, dear members of parliament, is the overwhelming majority in Saxony-Anhalt. That is the democratic Saxony-Anhalt, which we, as Alliance 90/The Greens, stand up for. And we stand on the side of these people. We Germans can be very proud of the democratic structures we have built up since the Second World War."

A similar example can be found in the speech by Henning Homann, MP for the in Sachsen, in February 29 2016. Again, the speech starts with calling out the way the radical-right does politics: "[...] To accuse the parties here in front of us of not doing so 
[putting forward proposals to effectively tackling the problems of the country] is bigotry. That is simple bigotry, and we will not let that pass. The fact that you end up re-electing a Secretary-General who thinks Mrs Merkel is a Stasi sleeper says more about you than it does about Mrs Merkel. You have finally said goodbye to serious politics, if you have ever pursued serious politics at all. When I listen to your words, I hear a very difficult relativisation. You shift the blame for the attacks in this country onto politics. There is no justification for violence. The argument that Mrs Merkel's refugee policy is to blame for the violence in this country is not valid. That is not acceptable. There is no relativisation of questioning the state's monopoly on the use of force and the dignity of human beings in this country. That must be clear to everyone in this country." Then, the speech immediately moves to a much more positive tone, to build a contrast with the MP's view of what is needed in the country: "What we need in Saxony is now more than ever a culture of courage. Many thousands are already involved today - from the church, from the student body, many teachers from the cultural sector, many entrepreneurs, people from sport, many people in socio-culture. These many thousands of people are, I think, something like a new citizens' movement in Saxony. They are the decent Saxons. They are our figurehead. That is why these people need our support. It must be the central message of today that we bring these people out of the shadows into the light. These are the people we can be proud of. These are the people we are also happy when they are covered in the media."

\section{F Further details on the qualitative analyses}

The qualitative analyses shown in the main text show how often politicians use each type of reaction to radical-right success and rhetoric. In coding these, we also coded the justification given for each of these reactions. Since these are not central to our argument, we detail them in this appendix.

We found that, in almost half the speeches in our random sample, politicians reacted to radical-right success and rhetoric by calling out the norm-breaching nature of its general way of doing politics. Table F.1 shows the main justifications that politicians used for it.

Table F.1: Main justifications for MPs to call out norm-breaching behavior by radicalright politicians in their general political style.

\begin{tabular}{ccc}
\hline \hline Justification & Absolute frequency & Proportion of total speeches in sample \\
\hline Right-wing extremism, discrimination, anti-democratic, agitation, social division, against minorities & 80 & 0.22 \\
Un-constitutional, fraud, crimes & 16 & 0.04 \\
Populism: un-constructive, sensationalism, hypocritical, self-victimisation, fear-mongering, scapegoating & 59 & 0.16 \\
Lying, half-truths, disinformation & 12 & 0.03 \\
Fear-mongering, emotionalization, stirring up resentment & 17 & 0.05 \\
\hline
\end{tabular}

We also found evidence of politicians calling out the norm-breaching behavior of the radical right in their legislative behavior, specifically. Table F.2 shows the main ways in which politicians justified doing so. 
Table F.2: Main justifications for MPs to call out norm-breaching behavior by radicalright politicians in their behavior in parliament.

\begin{tabular}{ccc}
\hline \hline Justification & Absolute frequency & Proportion of total speeches in sample \\
\hline Hate speech, insulting or inhuman language, political agitation & 27 & 0.08 \\
Nazi rhetoric, racism, anti-democratic language, far-right rhetoric & 14 & 0.04 \\
Populism: un-constructive, sensationalism, hypocritical, self-victimisation, fear-mongering, scapegoating & 50 & 0.14 \\
Lying, half-truths, disinformation & 20 & 0.06 \\
\hline
\end{tabular}

Finally, we also find many instances of politicians making efforts to distance themselves and their party from the radical-right rhetoric and discourse. Table F.3 shows the main ways in which they did so. It should be noted that all of them involve the use of positive emotional discourse to make a contrast with the radical right.

Table F.3: Main justifications for MPs to contrast themselves and their party to the radical right.

\begin{tabular}{ccc}
\hline \hline Justification & Absolute frequency & Proportion of total speeches in sample \\
\hline Praising the region / people in the region / volunteers in the region & 20 & 0.06 \\
Praising the EU & 8 & 0.02 \\
Emphasising democratic norms / rule of law / contrast between democratic parties and AfD & 26 & 0.07 \\
Call for tolerance and oppeness, anti-racism, anti-fascism & 39 & 0.05 \\
Praising own policies / work / achievements & 46 & 0.11 \\
Praising their own style of debating / doing politics (e.g. constructive, rational, etc.) & 0.13 \\
\hline
\end{tabular}

It should be noted that some speeches provide no explicit justification for their reaction, while others provide more than one. For this reason, the sum of the number of speeches using one specific justification for a reaction does not necessarily add up to the total number of speeches that include each of the reactions, as shown in Table 2. It should also be noted that we report the proportion that each justification represents of the whole sample of 361 speeches, not just of speeches that include each of reactions that each table refers to. 